\title{
Activation of Type 5 Metabotropic Glutamate Receptors and Diacylglycerol Lipase- $\alpha$ Initiates 2-Arachidonoylglycerol Formation and Endocannabinoid-Mediated Analgesia
}

\author{
Laura C. Gregg, ${ }^{1 \star}$ Kwang-Mook Jung, ${ }^{3 *}$ Jessica M. Spradley, ${ }^{1}$ Rita Nyilas, ${ }^{4}$ Richard L. Suplita II, ${ }^{2}$ Andreas Zimmer, ${ }^{5}$ \\ Masahiko Watanabe, ${ }^{6}$ Ken Mackie, ${ }^{7}$ István Katona, ${ }^{4}$ Daniele Piomelli, ${ }^{3,8}$ and Andrea G. Hohmann ${ }^{1,2,7}$ \\ ${ }^{1}$ Neuroscience Program, Biomedical and Health Sciences Institute, and 2Psychology Department, University of Georgia, Athens, Georgia 30602-3013, \\ ${ }^{3}$ Department of Pharmacology, University of California, Irvine, Irvine, California 92697, ${ }^{4}$ Institute of Experimental Medicine, Hungarian Academy of \\ Sciences, H-1083 Budapest, Hungary, ${ }^{5}$ Insitute of Molecular Psychiatry, University of Bonn, 53105 Bonn, Germany, ${ }^{6}$ Department of Anatomy, Hokkaido \\ University School of Medicine, Sapporo 060-8638, Japan, ${ }^{7}$ Department of Psychological and Brain Sciences, Indiana University, Bloomington, Indiana \\ 47405-2204, and ${ }^{8}$ Unit of Drug Discovery and Development, Italian Institute of Technology, 16163 Genoa, Italy
}

Acute stress reduces pain sensitivity by engaging an endocannabinoid signaling circuit in the midbrain. The neural mechanisms governing this process and molecular identity of the endocannabinoid substance(s) involved are unknown. We combined behavior, pharmacology, immunohistochemistry, RNA interference, quantitative RT-PCR, enzyme assays, and lipidomic analyses of endocannabinoid content to uncover the role of the endocannabinoid 2-arachidonoyl-sn-glycerol (2-AG) in controlling pain sensitivity in vivo. Here, we show that footshock stress produces antinociception in rats by activating type 5 metabotropic glutamate receptors (mGlu ( $_{5}$ in the dorsolateral periaqueductal gray (dlPAG) and mobilizing 2-AG. Stimulation of mGlu $_{5}$ in the dlPAG with DHPG [(S)-3,5dihydroxyphenylglycine] triggered 2-AG formation and enhanced stress-dependent antinociception through a mechanism dependent upon both postsynaptic diacylglycerol lipase (DGL) activity, which releases 2-AG, and presynaptic $\mathrm{CB}_{1}$ cannabinoid receptors. Pharmacological blockade of DGL activity in the dlPAG with RHC80267 [1,6-bis(cyclohexyloximinocarbonylamino)hexane] and (-)tetrahydrolipstatin (THL), which inhibit activity of DGL- $\alpha$ and DGL- $\beta$ isoforms, suppressed stress-induced antinociception. Inhibition of DGL activity in the dIPAG with THL selectively decreased accumulation of 2-AG without altering levels of anandamide. The putative 2-AG-synthesizing enzyme DGL- $\alpha$ colocalized with $\mathrm{mGlu}_{5}$ at postsynaptic sites of the dIPAG, whereas $\mathrm{CB}_{1}$ was confined to presynaptic terminals, consistent with a role for $2-\mathrm{AG}$ as a retrograde signaling messenger. Finally, virally mediated silencing of DGL- $\alpha$, but not DGL- $\beta$, transcription in the dlPAG mimicked effects of DGL inhibition in suppressing both endocannabinoid-mediated stress antinociception and 2-AG formation. The results indicate that activation of the postsynaptic $\mathrm{mGlu} \mathrm{u}_{5}-\mathrm{DGL}-\alpha$ cascade triggers retrograde 2 -AG signaling in vivo. This pathway is required for endocannabinoid-mediated stress-induced analgesia.

\section{Introduction}

Endocannabinoids are phospholipid-derived messengers that regulate central neurotransmission by activating presynaptic $\mathrm{CB}_{1}$-type cannabinoid receptors (Wilson and Nicoll, 2001; Alger,

Received Dec. 31, 2011; revised May 11, 2012; accepted May 17, 2012.

Author contributions: K.-M.J., M.W., I.K., D.P., and A.G.H. designed research; L.C.G., K.-M.J., J.M.S., R.N., R.L.S., and A.G.H. performed research; K.-M.J., M.W., K.M., and D.P. contributed unpublished reagents/analytic tools; L.C.G., K.-M.J., J.M.S., R.N., and A.G.H. analyzed data; L.C.G., K.-M.J., J.M.S., R.N., K.M., I.K., D.P., and A.G.H. wrote the paper.

This work was supported by NIH Grants DA021644 and DA022478 (A.G.H., D.P.), and DA011322 and DA021696 (K.M.), and by a grant from Switzerland through the Swiss Contribution (SH7/2/18), the Hungarian Scientific Research Fund-Norwegian Financial Mechanism Joint Program (NNF 78918), and the European Research Council Grant 243153 (R.N., I.K.). We are grateful to Nathan Bolton, Erika Tischler, and Balázs Pintér for technical assistance. We also thank László Barna, the Nikon Microscopy Center at Institute of Experimental Medicine, Nikon Austria GmbH, and Auro-Science Consulting, Ltd., for kindly providing microscopy support.

*L.C.G. and K.-M.J. contributed equally to this work.

Correspondence should be addressed to either of the following: Daniele Piomelli, Department of Pharmacology, University of California, Irvine, Irvine, CA 92697, E-mail: piomelli@uci.edu; or Andrea G. Hohmann, Department of Psychological and Brain Sciences, Indiana University, Bloomington, IN 47401, E-mail: hohmanna@indiana.edu.

DOI:10.1523/JNEUROSCI.0013-12.2012

Copyright $\odot 2012$ the authors $\quad 0270-6474 / 12 / 329457-12 \$ 15.00 / 0$
2002; Gerdeman et al., 2002; Carey et al., 2011). One of these neuromodulatory lipids, the arachidonic acid derivative 2arachidonoyl-sn-glycerol (2-AG) (Mechoulam et al., 1995; Sugiura et al., 1995), is thought to act as a retrograde signal at excitatory and inhibitory synapses throughout the brain (Robbe et al., 2002; Chevaleyre and Castillo, 2003; Uchigashima et al., 2007; Gao et al., 2010; Tanimura et al., 2010). Evidence suggests that 2-AG is released in a stimulus-dependent manner by the consecutive action of two enzymes found at postsynaptic spines, phospholipase C- $\beta$ (PLC- $\beta$ ) and diacylglycerol lipase- $\alpha$ (DGL- $\alpha$ ) (Stella et al., 1997; Hashimotodani et al., 2005, 2008, 2011; Lafourcade et al., 2007). PLC- $\beta$ hydrolyzes phosphatidylinositol 4,5-bisphosphate to generate 1,2-diacylglycerol (DAG), while DGL- $\alpha$ cleaves newly formed DAG to generate 2-AG (Piomelli, 2003; Jung et al., 2007). At central synapses, DGL- $\alpha$ often colocalizes with type 5 metabotropic glutamate receptors $\left(\mathrm{mGlu}_{5}\right)$, combining into a multiprotein complex that may initiate retrograde endocannabinoid signaling (Maejima et al., 2001; Uchigashima et al., 2007; Nyilas et al., 2009). Indeed, mGlu ac- $^{-}$ 
tivation stimulates DGL- $\alpha$ to trigger the biosynthesis of 2-AG in vitro (Jung et al., 2005, 2007) and depresses synaptic transmission through a $\mathrm{CB}_{1}$-dependent mechanism (Uchigashima et al., 2007). However, direct evidence that this pathway controls 2-AG formation in vivo has remained elusive. Genetic deletion of DGL- $\alpha$ decreases 2-AG levels in mouse brain and suppresses retrograde endocannabinoid signaling (Gao et al., 2010; Tanimura et al., 2010). Nevertheless, DGL- $\alpha$ deletion is accompanied by substantial alterations in the steady-state levels of other signaling lipids, including arachidonic acid and the endocannabinoid anandamide (Gao et al., 2010; Tanimura et al., 2010). Thus, alternative approaches are required to unequivocally identify the role of 2-AG in behavior. The physiological mechanisms that control 2-AG signaling in vivo and conditions under which such signaling is engaged remain unknown.

Exposure to an acute environmental stressor causes a profound antinociceptive response in rats that is partially dependent on endocannabinoid signaling (Hohmann et al., 2005; Suplita et al., 2005, 2006; Nyilas et al., 2009). The endocannabinoidmediated component of this stress-induced antinociceptive response is enhanced by blocking the enzymatic degradation of 2-AG in the dorsolateral periaqueductal gray (dlPAG) of the midbrain (Hohmann et al., 2005). These results provide an experimental framework in which to investigate the functional significance of 2-AG signaling in vivo. Here, we used a multidisciplinary approach to elucidate the molecular mechanisms that govern 2-AG formation in the PAG and identify the resulting effects on behavior. These studies combined behavior, pharmacology, immunohistochemistry (at light- and electronmicroscopic levels), RNA interference, quantitative RT-PCR, enzyme assays, and targeted lipidomic analyses to uncover the role of 2-AG signaling in controlling pain sensitivity in vivo. Our findings indicate that exposure to an environmental stressor modulates nociception by triggering a postsynaptic $\mathrm{mGlu}_{5}-$ DGL- $\alpha-2-A G$ cascade in neurons of the dlPAG. This process initiates local retrograde signaling that is specifically mediated by 2-AG acting at presynaptic $\mathrm{CB}_{1}$ receptors.

\section{Materials and Methods}

Subjects. Male Sprague Dawley rats (275-350 g; Harlan) were used for in vivo studies. Procedures were approved by the Institutional Animal Care and Use Committee and followed guidelines of the International Association for the Study of Pain (Zimmermann, 1983). The experimenter was blinded to experimental conditions in all studies.

Cannulae implantation. Rats were anesthetized (intraperitoneally) with Nembutal $(25 \mathrm{mg} / \mathrm{kg})$ and ketamine $(40 \mathrm{mg} / \mathrm{kg})$. Stainless-steel guide cannulae (24 g; Small Parts) were implanted unilaterally $2 \mathrm{~mm}$ above the dlPAG $[+1.6 \mathrm{~mm}$ anteroposterior $(\mathrm{AP}),+0.67 \mathrm{~mm}$ lateromedial (LM), $-5.35 \mathrm{~mm}$ dorsoventral (DV), relative to lambda, the midline suture, and the skull surface, respectively] or deliberately off-site using a rat brain atlas (Paxinos and Watson, 1998). Stainless-steel insect pins prevented occlusion of cannulae. On test days, the microinjection needle was inserted $2 \mathrm{~mm}$ beyond the cannulae to hit the PAG at the stereotaxic coordinate (DV) designated above. Animals were allowed to recover 5-7 $\mathrm{d}$ before testing.

Drug preparation and administration. (S)-3,5-Dihydroxyphenylglycine (DHPG) was from Tocris Bioscience. N-(Piperidin-1-yl)-5-(4-chlorophenyl)-1-(2,4-dichlorophenyl)-4-methyl-1 $H$-pyrazole-3-carboxamide (SR141716) (rimonabant) was from NIDA. N-Formyl-L-leucine (1S)-1-[[(2S,3S)-3-hexyl-4-oxo-2-oxetanyl $]$ methyl] dodecyl ester [(-)tetrahydrolipstatin (THL)] and 2-methyl-6-(phenylethynyl)pyridine hydrochloride (MPEP) were from Sigma-Aldrich. 1,6-bis(cyclohexyloximinocarbonylamino)hexane (RHC80267) was from Calbiochem. Drugs were dissolved in a DMSO vehicle and delivered intracranially using our previously published methods (Hohmann et al., 2005). Doses were those used previously (Hohmann et al., 2005; Nyilas et al., 2009) or selected based upon pilot studies performed in our laboratory. Animals received a single intracranial injection, administered at a speed of $30 \mathrm{nl} / \mathrm{s}$ with a microinfusion pump (UltraMicroPump II; World Precision Instruments). To ensure that injection spread did not differ between studies, multiple compounds were always coinjected in a single injection volume $(1 \mu \mathrm{l})$. The vehicle and injection volume was constant in all studies using pharmacological manipulations. Effects of pharmacological manipulations were always compared with vehicle controls tested concurrently.

Preparation of small hairpin RNA expressing adenoassociated virus. We generated small hairpin RNA (shRNA) constructs containing both a cytomegalovirus promoter-driven green fluorescent protein (GFP) and a U6 promoter-driven shRNA expression system (Jung et al., 2007). shRNAs were designed using BLOCK-iT RNAi Designer (https://rnaidesigner.invitrogen. com/rnaiexpress/), and corresponding oligonucleotides were synthesized. Sense and antisense oligonucleotides were annealed and ligated into pENTR entry vector (Invitrogen) to generate U6 promoter-shRNA-Pol III terminator cassette. The oligonucleotides used were as follows: LacZi, 5' CACCGCTACACAAATCAGCGATTTCGAAAAATCGCTGATTTGTG TAG-3' (top)and5'-AAAACTACACAAATCAGCGATTTTTCGAAATC GCTGATTTGTGTAGC-3' (bottom); DGL- $\alpha$ i, 5' -CACCGCTACAAA GAAGTCTGCTACTCGAAAGTAGCAGACTTCTTTGTAGC-3' (top) and $5^{\prime}$-AAAAGCTACAAAGAAGTCTGCTACTTTCGAGTAGCAGAC TTCTTTGTAGC-3' (bottom); DGL- $\beta$ i, 5' $5^{\prime}$-CACCGGATCGCCAGTC TGACGTTATCGAAATAACGTCAGACTGGCGATCC-3' (top) and 5' -AAAAGGATCGCCAGTCTGACGTTATTTCGATAACGTCAGA CTGGCGATCC-3' (bottom). shRNA plasmids were tested for silencing activity in cultured cells, and shRNA sequences were moved into an adenoassociated virus (AAV) vector (pAAV2-hrGFP; Stratagene) as described previously (Jung et al., 2007). Adenoassociated viruses were prepared and purified, and viral genome titers were determined (Applied Viromics) (Zi-AAV, 7.6e11 GC/ml; $\alpha \mathrm{i}, 1.2 \mathrm{e} 12 \mathrm{GC} / \mathrm{ml} ; \beta \mathrm{i}, 5.3 \mathrm{e} 11 \mathrm{GC} / \mathrm{ml}$ ).

Behavioral testing. Stress antinociception was quantified behaviorally by measuring the latency for a rat to remove its tail from a radiant heat source (IITC; model 33A) (Hohmann et al., 2005; Nyilas et al., 2009). A cutoff latency (10 s) was used to prevent tissue damage. Stable baseline withdrawal responses were established before drug manipulations. Animals received a single intracranial injection, administered at a speed of 30 $\mathrm{nl} / \mathrm{s}$, with a microinfusion pump (UltraMicroPump II; World Precision Instruments). The microinjection needle remained in place for $60 \mathrm{~s}$ following infusion. In separate studies, groups of rats received intra-dlPAG injections of one of the following: (1) vehicle or the $\mathrm{mGlu}_{5}$ antagonist $\operatorname{MPEP}\left(2.3 \times 10^{-5} \mu \mathrm{g}\right.$ or $\left.2.3 \mu \mathrm{g}\right)(n=7-8$ per group); (2) vehicle or the group I mGlu agonist DHPG (0.02 or $0.2 \mu \mathrm{g})(n=6$ per group); (3) vehicle, DHPG $(0.2 \mu \mathrm{g})$, or DHPG $(0.2 \mu \mathrm{g})$ coadministered with MPEP $\left(2.3 \times 10^{-5} \mu \mathrm{g}\right)(n=5-8$ per group); (4) vehicle, DHPG $(0.2 \mu \mathrm{g})$, the $\mathrm{CB}_{1}$ antagonist rimonabant $(0.1 \mu \mathrm{g})$ or DHPG $(0.2 \mu \mathrm{g})$ coadministered with rimonabant $(0.1 \mu \mathrm{g})(n=6$ per group); (5) vehicle or the diacylglycerol lipase inhibitor RHC80267 $(1,10$ or $100 \mu \mathrm{g})(n=6-7$ per group); (6) vehicle or the diacylglycerol lipase inhibitor THL $(0.1,1$, or 10 $\mu \mathrm{g})(n=7-9$ per group); and (7) vehicle, DHPG $(0.2 \mu \mathrm{g})$, or DHPG $(0.2$ $\mu \mathrm{g})$ coadministered with THL $(0.1 \mu \mathrm{g})(n=9-11$ per group). In control experiments, active compounds and the vehicle were also injected deliberately off-site of the dIPAG to control for site specificity $(n=4-8$ per group). Immediately following microinjection, tail-flick latencies were assessed at 2 min intervals and averaged to assess changes in basal nociceptive thresholds induced by pharmacological manipulations before footshock. Stress antinociception was induced 5 min following a single unilateral microinjection as described previously (Hohmann et al., 2005). The use of unilateral microinjections enabled us to maintain consistency with our previously published work while also minimizing possible stress associated with performing multiple injections that could otherwise alter endogenous analgesic tone. The experimenter was blinded to experimental conditions in all studies. Tail-flick latencies were measured following footshock at $2 \mathrm{~min}$ intervals over 40-60 min. Consecutive measurements were averaged for each rat before (baseline) and after (postshock) exposure to the footshock stressor to create two-point blocks, used for repeated-measure statistical analyses, as described previously (Hohmann et al., 2005). 
In vivo $R N A$ silencing. Viruses were injected bilaterally into the dlPAG ( $n=12$ per group) or deliberately off-site of the dlPAG ( $n=5-6$ per group) under isoflurane anesthesia. Separate groups of rats received infusions ( $0.4 \mu \mathrm{l}$ per side) of either the DGL- $\alpha$ silencing virus (DGL- $\alpha \mathrm{i}$ ), the DGL- $\beta$ silencing virus (DGL- $\beta \mathrm{i}$ ), or the LacZ control virus ( $\mathrm{LacZi}$ ) in a single survival surgery. Naive animals $(n=9)$ were left intact. Two weeks following surgery (or no surgery), tail-flick latencies were assessed before (baseline) and after exposure to footshock ( $3 \mathrm{~min}, 3 \mathrm{~mA}$; MED Associates) at $2 \mathrm{~min}$ intervals. Tissue samples were obtained from separate groups of rats killed at the time point $(1 \mathrm{~min})$ and postsurgical delay ( 2 weeks) associated with maximal suppression of stress antinociception in pilot studies (compared with animals killed 1 or 4 weeks after viral infection) (data not shown).

Histology. Injection sites were confirmed in Nissl-stained sections (40 $\mu \mathrm{m})$ by an experimenter blinded to experimental conditions. GFP localization was assessed using a Leica DMLB fluorescence microscope to confirm viral infection and map injection sites.

Ex vivo studies: tissue generation. To generate tissue for ex vivo experiments, animals with chronic indwelling cannulae were habituated to handling and the guillotine for at least $5 \mathrm{~d}$ before the experiment. Behaviorally active doses of DHPG $(0.2 \mu \mathrm{g})$, THL $(10 \mu \mathrm{g})$, or vehicle were microinjected into the dlPAG. Rats were decapitated at behaviorally relevant time points following termination of footshock (i.e., when effects of pharmacological manipulations were maximal; 15 min for DHPG; 2 min for THL; 1 min for RNA silencing). Whole brains were rapidly dissected, snap frozen in isopentane $\left(-30^{\circ} \mathrm{C}\right)$, and stored $\left(-80^{\circ} \mathrm{C}\right)$ until use. Punches ( $1 \mathrm{~mm}$ deep) containing the entire PAG were taken with a 2-mm-diameter sample corer between plate 50 and plate 44 of the rat brain atlas (Paxinos and Watson, 1998). Coronal sections were obtained with a cryostat before and after the punch to verify that the level of each punch was consistent between animals. To control for site specificity, equivalently sized punches were obtained deliberately off-site from the midbrain reticular formation in the same brains.

Lipid extractions. Punches obtained from frozen brains were homogenized in methanol (1 ml per punch) containing heptadecenoylethanolamide and $\left[{ }^{2} \mathrm{H}_{8}\right]-2-\mathrm{AG}$ (Cayman Chemical) as internal standards. Lipids were extracted with methanol/chloroform/water (1:2:1, by vol). Organic phases were collected and dried under $\mathrm{N}_{2}$. Endocannabinoids were fractionated by open-bed silica gel column chromatography, as described previously (Giuffrida et al., 2000). Lipids were reconstituted in chloroform and loaded onto small glass columns packed with Silica Gel G ( $60 \AA$ 230-400 Mesh ASTM; Whatman). Anandamide and 2-AG were eluted with 9:1 chloroform/methanol (v/v). Eluates were dried under $\mathrm{N}_{2}$ and reconstituted in $70 \mu \mathrm{l}$ of chloroform/methanol $(1: 3, \mathrm{v} / \mathrm{v})$ for liquid chromatography/mass spectrometry (LC/MS) analysis.

In vitro DGL assay. DGL activity assay was performed as described previously (Jung et al., 2007). Brain punches were homogenized in $50 \mathrm{~mm}$ Tris- $\mathrm{HCl}, \mathrm{pH} 7.0$, and homogenates were centrifuged $(800 \times g$ for $5 \mathrm{~min}$ at $\left.4^{\circ} \mathrm{C}\right)$. DGL activity was measured using the supernatant (100 $\mu \mathrm{g}$ proteins) at $37^{\circ} \mathrm{C}$ for $30 \mathrm{~min}$ in $50 \mathrm{~mm}$ Tris- $\mathrm{HCl}, \mathrm{pH} \mathrm{7.0,} \mathrm{containing} 0.1 \%$ Triton X-100, and the substrate diheptadecanoylglycerol (50 $\mu \mathrm{M})$. Reactions were stopped by adding chloroform/methanol (1:1) containing $\left[{ }^{2} \mathrm{H}_{8}\right]-2-\mathrm{AG}$. Lipids were extracted, and the levels of reaction product monoheptadecanoylglycerol $[\mathrm{M}+\mathrm{Na}]^{+}(\mathrm{m} / \mathrm{z}=367)$ were quantified by LC/MS using $\left[{ }^{2} \mathrm{H}_{8}\right] 2-\mathrm{AG}(m / z=409)$ as an internal standard.

$m R N A$ quantitation. We used a quantitative real-time PCR method to analyze mRNAs. We extracted RNA from brain punches using a TRIzol (Invitrogen)/RNeasy (QIAGEN) hybrid protocol. First-strand complementary DNAs were synthesized from $2 \mu \mathrm{g}$ of the total RNA using SuperScript II RNase H reverse transcriptase (Invitrogen) and oligo- $\mathrm{dT}_{12-18}$ primers, for $50 \mathrm{~min}$ at $42^{\circ} \mathrm{C}$. Quantitative PCR was conducted using Mx3000P system (Stratagene) by a TaqMan method. DGL mRNA levels were normalized using GAPDH (glyceraldehyde3-phosphate dehydrogenase) as an internal standard. The primer/ probe set were as follows: for rat DGL- $\alpha$ (GI: 54312093), forward, 5' -CCAGGCCTTTGGGCG-3'; reverse, 5' -GCCTACCACAATCAGG CCAT-3'; TaqMan probe, 5' -ACCTGGGCCGTGGAACCAAACA-3', for rat DGL- $\beta$ (GI: 34870416), forward, $5^{\prime}$-AGGACTGCGTGGCCCAC-
3'; reverse, 5'-CGTTGACCAGTCTTCGATAAATGT-3'; TaqMan probe, 5'-AGGGAATTGCTCAAGCGGCCAGA-3'.

LC/MS analyses. We measured endocannabinoids using an 1100-LC system coupled to a 1946A-MS detector (Agilent Technologies) equipped with an electrospray ionization interface in punches obtained from each frozen sample. Lipids were separated using an XDB Eclipse $\mathrm{C} 18$ column $(50 \times 4.6 \mathrm{~mm}$; inner diameter, $1.8 \mu \mathrm{m}$; Zorbax $)$, eluted with a gradient of methanol in water (from 75 to $85 \%$ in $2.5 \mathrm{~min}, 85$ to $90 \%$ in $5 \mathrm{~min}$, and then $100 \%$ in $0.5 \mathrm{~min}$ ) at a flow rate of $1.0 \mathrm{ml} / \mathrm{min}$. Column temperature was kept at $40^{\circ} \mathrm{C}$. MS detection was in the positive ionization mode, capillary voltage was set at $3 \mathrm{kV}$, and fragmentor voltage was varied from $120 \mathrm{~V}$. $\mathrm{N}_{2}$ was used as drying gas at a flow rate of $13 \mathrm{~L} / \mathrm{min}$ and a temperature of $350^{\circ} \mathrm{C}$. Nebulizer pressure was set at $60 \mathrm{psi}$. Quantifications were conducted using an isotope-dilution method, monitoring $\mathrm{Na}^{+}$adducts of the molecular ions $\left([\mathrm{M}+\mathrm{Na}]^{+}\right)$.

Immunohistochemistry for $m G l u_{5}$. Adult male Sprague Dawley rats ( $n=5 ; \sim 70$ d of age) were perfused transcardially under deep Nembutal $(50 \mathrm{mg} / \mathrm{ml})$ anesthesia with $100 \mathrm{ml}$ of cold heparinized $0.1 \mathrm{M}$ PBS followed by $300 \mathrm{ml}$ of cold $4 \%$ paraformaldehyde. Brains were collected, postfixed ( $4 \%$ paraformaldehyde at $4^{\circ} \mathrm{C}$ for $24 \mathrm{~h}$ ), and cryoprotected in $30 \%$ sucrose $\left(4^{\circ} \mathrm{C}\right.$ for at least $\left.72 \mathrm{~h}\right)$. Free-floating alternating sections ( 30 $\mu \mathrm{m})$ were kept in wells of $0.1 \mathrm{M}$ PBS. Endogenous peroxidases were inactivated by incubation in $0.1 \mathrm{M}$ PBS containing $0.3 \% \mathrm{H}_{2} \mathrm{O}_{2}$. Tissues were blocked (1.5\% goat serum) and incubated for $1 \mathrm{~h}$ at $20^{\circ} \mathrm{C}$ and $48 \mathrm{~h}$ at $4^{\circ} \mathrm{C}$ in polyclonal 21 residue synthetic peptide rabbit anti-mGlu $\mathrm{mi}_{5}$ directed against the $\mathrm{C}$-terminal of $\mathrm{mGlu}_{5}$ with a lysine added to the N-terminal (Millipore; 1:10,000). Antibodies were diluted in $0.4 \%$ Triton PBS. Biotinylated goat anti-rabbit IgG (1:600; Vector Laboratories) served as the secondary antibody in which the tissues incubated for $1 \mathrm{~h}$ at $20^{\circ} \mathrm{C}$. Tissues were incubated with Elite ABC kit (1:200; Vector Laboratories) for $1 \mathrm{~h}$, followed by $5 \mathrm{~min}$ incubation in diaminobenzidine solution $(0.5 \mathrm{mg} / \mathrm{ml} ; \mathrm{KPL})$ containing $0.1 \% \mathrm{H}_{2} \mathrm{O}_{2}$, and intensified with $2 \% \mathrm{Ni}$ $\mathrm{SO}_{4} 6 \mathrm{H}_{2} \mathrm{O}$. Sections were mounted onto gelatin-subbed slides, air-dried, dehydrated in ascending concentrations of ethanol, cleared in xylene, and coverslipped. Preabsorption controls performed previously (Alvarez et al., 2000) with the same commercially available anti-mGlu antibody $_{5}$ showed specificity. Additional controls included primary and secondary antibody omissions. Staining in our hands was absent in all control conditions and was consistent with expression patterns reported previously (Azkue et al., 1997). Images were captured using a Leica DMLB light microscope and a Retiga 1300 digital camera. Brightness/contrast was adjusted for the entire image in Adobe Photoshop, so that backgrounds appeared similar.

Light and electron microscopy for $C B_{1}, D G L-\alpha$, and $m G l u_{5}$. Experiments were performed according to institutional guidelines of ethical code and the Hungarian Act of Animal Care and Experimentation (1998. XXVIII. Section 243/1998). Brains were fixed in $4 \%$ paraformaldehyde and processed for immunoperoxidase and preembedding immunogold labeling as described previously (Katona et al., 2006). For light- and electron-microscopic analyses, sections from adult C57BL/6J wild-type mice and their $\mathrm{CB}_{1}$ knock-out (Zimmer et al., 1999) littermates (four males, 50 and 58 d of age; two females, $76 \mathrm{~d}$ of age) and three male Wistar rats (47-80 d of age) were used. For primary antibodies, we used affinity-purified guinea pig or goat anti- $\mathrm{CB}_{1}$ antibodies [1:200-1:500 (Fukudome et al., 2004); or 1:2000, $\sim 1$ or 0.225 $\mu \mathrm{g} / \mathrm{ml}$, respectively], a rabbit anti-DGL- $\alpha$ antibody $[1: 1000-1: 3000 ; \sim 0.3-1$ $\mu \mathrm{g} / \mathrm{ml}$; termed "INT" (Katona et al., 2006)], and an affinity-purified guinea pig anti-mGlu ${ }_{5}$ antibody $[1: 300 ; \sim 1 \mu \mathrm{g} / \mathrm{ml}$ (Uchigashima et al., 2007)]. In immunoperoxidase stainings, primary antibody incubations were followed by application of the appropriate biotinylated secondary antibody (1:300-1:500; Vector Laboratories) and incubation with avidinbiotinylated-horseradish peroxidase complex (1:500; Elite-ABC; Vector Laboratories); the immunoperoxidase reaction was developed using $3,3^{\prime}$-diaminobenzidine $(\mathrm{DAB})$ as the chromogen. In the doubleimmunostaining experiments, sections were developed first for immunogold and then for immunoperoxidase labeling. In the immunogold staining procedure, sections were incubated in $0.8 \mathrm{~nm}$ gold-conjugated secondary antibody (1:50; AURION), and then sections were silver intensified using the R-GENT SE-EM (AURION). Sections for electron microscopy were treated with $\mathrm{OsO}_{4}$ and uranyl acetate, dehydrated in an 
ascending series of ethanol and acetonitrile, and embedded in Durcupan (ACM; Fluka). Areas of interest were reembedded and resectioned, serial ultrathin sections ( $60 \mathrm{~nm}$ thickness) were collected on Formvar-coated single-slot grids, and they were analyzed using electron microscopy.

Statistical analysis. Data were analyzed by repeated-measures ANOVA, ANOVA, and planned comparison $t$ tests, one- or two-tailed, as appropriate. The Greenhouse-Geisser correction was applied to repeated factors. Post hoc comparisons were performed using Fisher's protected least-squares difference (PLSD) test (in the case of multiple comparisons) or Dunnett's test (in the case of comparisons to control) with $p<0.05$ considered significant. SPSS (version 16.0; SPSS, Inc.) and GraphPad Prism (version 5) statistical software were used. Every two consecutive tail-flick latencies were averaged for each animal before (baseline) and after (postshock) exposure to footshock to form two-point blocks used in data analyses. Postinjection tail-flick latencies, determined immediately before footshock, were averaged into a single block for each animal and averaged across animals for each drug treatment as described previously (Hohmann et al., 2005).

\section{Results}

$\mathrm{mGlu}_{5}$ initiates stress antinociception and 2-AG mobilization

To examine the role of $\mathrm{mGlu}_{5}$ in the expression of endocannabinoid-mediated stress antinociception, we first mapped the distribution of $\mathrm{mGlu}_{5}$ in the rat PAG. We observed dense and specific immunoreactivity for $\mathrm{mGlu}_{5}$ in the dorsolateral (dl) columns of the rat PAG (Fig. $1 A-D$ ), a midbrain structure implicated in nociceptive signaling (Walker et al., 1999; Hohmann et al., 2005) and defensive behavior (Bandler et al., 2000). Pharmacological experiments subsequently revealed that $\mathrm{mGlu}_{5}$ signaling in the dlPAG contributes to stress antinociception. Microinjection of the $\mathrm{mGlu}_{5}$ antagonist MPEP into the dlPAG suppressed $\left(F_{(1,19)}=8.50 ; p=0.002\right)$ the antinociceptive effect produced by a brief acute stress ( 3 min continuous electric footshock), and these effects were time dependent $\left(F_{(45,285)}=109.7 ; p<0.0001\right)$ (Fig. 1E,F). The high dose of MPEP suppressed stress antinociception relative to treatment with either the vehicle $(p=0.001)$ or the low dose of MPEP ( $p=0.038$ ), whereas the low dose of MPEP did not reliably alter stress antinociception $(p=0.09)$. By contrast, basal nociceptive thresholds, assessed immediately before exposure to the stressor, were unaltered by pharmacological manipulations (Fig. 1E). Consistent with the findings outlined above, microinjections of DHPG, a group I ( $\mathrm{mGlu}_{5}$ and $\left.\mathrm{mGlu}_{1}\right)$ agonist, into the dlPAG increased the magnitude $\left(F_{(2,15)}=8.11\right.$; $p=0.004)$ and altered the time course $\left(F_{(30,225)}=2.51 ; p=\right.$ $0.006)$ of stress antinociception without changing basal nociceptive thresholds (Fig. 2A). Post hoc comparisons revealed that both the high $(p=0.002)$ and low $(p=0.005)$ doses of DHPG enhanced stress antinociception. The effect of DHPG was also confined to the dlPAG because off-site injections of DHPG $(0.2 \mu \mathrm{g})$ failed to alter stress antinociception $(p=0.402$; Fig. $2 B$ ). More-
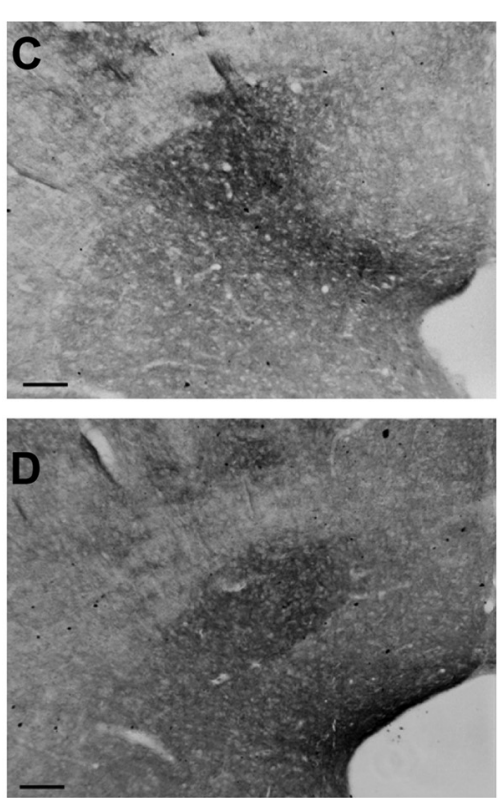

$\mathbf{F}$
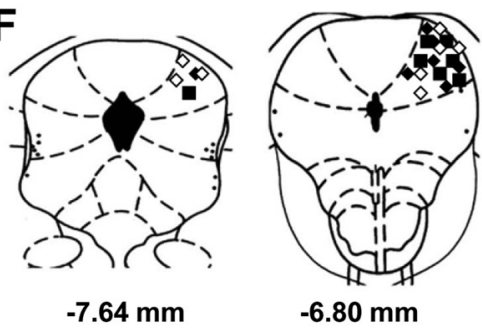

$-7.64 \mathrm{~mm}$

Figure 1. $\mathrm{mGlu}_{5}$ in the dIPAG is involved in stress-induced analgesia. $A-D$, Light micrographs show dense and specific immu-

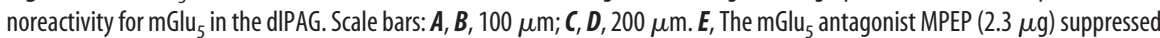

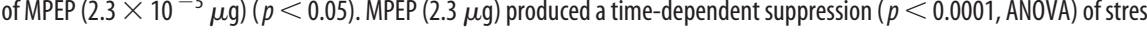
ntinociception without altering the basal nociceptive threshold. Antinociception was measured as the tail-flick latency. F, Microvehicle $(\diamond)$. Data are expressed as the mean \pm SEM. ${ }^{*} p<0.05$ versus control; ${ }^{++} p<0.001,{ }^{+} p<0.05$ versus all conditions (ANOVA, Fisher's PLSD test; $n=7-8$ per group).

over, microinjection of DHPG $(0.2 \mu \mathrm{g})$ into the dlPAG potentiated both the duration $\left(F_{(30,240)}=3.36 ; p=0.004\right)$ and magnitude $\left(F_{(2,16)}=6.47 ; p=0.009\right)$ of stress antinociception relative to vehicle $(p=0.01)$. This effect was prevented ( $p=$ 0.05 ) by treatment with the $\mathrm{mGlu}_{5}$ antagonist MPEP, used at a dose $\left(2.3 \times 10^{-5} \mu \mathrm{g}\right.$; Fig. $\left.1 E\right)$ that did not influence nociception when administered alone (Fig. $2 C$ ). These results suggest that activation of $\mathrm{mGlu}_{5}$ in the dlPAG is both necessary and sufficient for the expression of endocannabinoid-mediated stressinduced antinociception.

If $\mathrm{mGlu}_{5}$ activation in the dPAG mobilizes an endocannabinoid messenger, then (1) DHPG microinjection into the dlPAG should cause on-demand mobilization of endocannabinoid mediators, and (2) local blockade of $\mathrm{CB}_{1}$ receptors should prevent the ability of DHPG to enhance stress-induced antinociception. In agreement with these predictions, liquid chromatography/ mass spectrometry analyses of midbrain punches containing the PAG showed that DHPG elicits a local accumulation of 2-AG $\left(t_{(13)}=2.93 ; p=0.006\right)$ (Fig. $\left.2 E\right)$, but not anandamide $(p=$ 0.727 ; Fig. $2 F$ ), in the PAG of rats subjected to footshock and killed at the peak of the DHPG-induced potentiation of stress antinociception. This effect was restricted to the PAG as no changes in either $2-\mathrm{AG}(p=0.818)$ or anandamide $(p=0.675)$ 

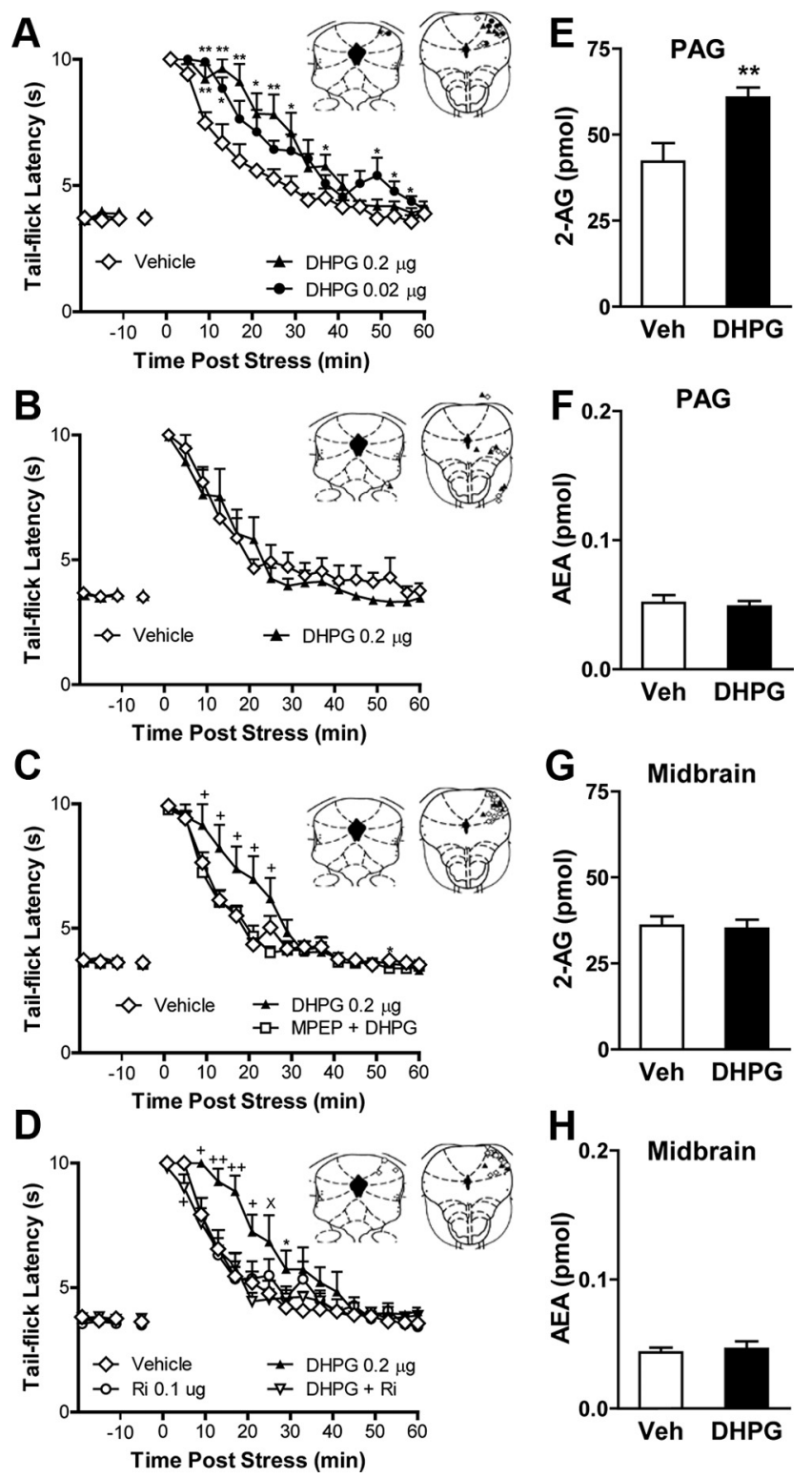

Figure 2. Activation of $\mathrm{mGlu}_{5}$ in the dIPAG enhances endocannabinoid-mediated stress antinociception by mobilizing the endocannabinoid 2-AG. $A$, Intra-dIPAG microinjection of the group I mGlu agonist DHPG $(0.02$ or $0.2 \mu \mathrm{g})$ enhanced ( $p<0.01$, ANOVA) stress antinociception relative to vehicle ( $p<0.01$ vs all comparisons). $B$, Off-site microinjection of DHPG $(0.2$ $\mu \mathrm{g})$ did not alter stress antinociception. C, D, DHPG-induced enhancement of stress antinociception $\left(p<0.01\right.$, ANOVA) was blocked by behaviorally inactive doses of MPEP $\left(2.3 \times 10^{-5}\right.$ $\mu \mathrm{g} ; p<0.01$ vs DHPG) (C) or the $\mathrm{CB}_{1}$ antagonist rimonabant $(0.1 \mu \mathrm{g} ; p=0.01$, ANOVA; $p<$ 0.01 vs DHPG) (D).E, $\boldsymbol{F}$, Intra-dIPAG microinjection of DHPG $(0.2 \mu \mathrm{g})$ increased 2-AG $(p<0.01$, one-tailed $t$ test) $(\boldsymbol{E})$ but not anandamide $(\boldsymbol{F})$ accumulation in the PAG relative to vehicle (Veh). Intra-dIPAG microinjection of DHPG $(0.2 \mu \mathrm{g})$ did not alter 2-AG $(\boldsymbol{G})$ or anandamide $(\boldsymbol{H})$ accumulation in the midbrain reticular formation. Data are expressed as mean \pm SEM. Insets,

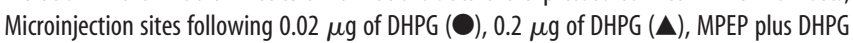
$(\square)$, Rimonabant (Ri) $(\bigcirc)$, DHPG plus Rimonabant $(\nabla)$, and vehicle $(\diamond)$ injections in the PAG $(\boldsymbol{A}, \boldsymbol{C}, \boldsymbol{D})$ or off-site $(\boldsymbol{B}) . \boldsymbol{A}-\boldsymbol{D},{ }^{* *} p<0.01,{ }^{*} p<0.05$ versus control; ${ }^{+} p<0.05$ versus all conditions; ${ }^{\times} p<0.05$ versus antagonist coadministration (ANOVA, Fisher's PLSD test; $n=$ $6-8$ per group). $\boldsymbol{E}-\boldsymbol{H}^{*}{ }^{* *} p<0.01$ ( $t$ test; $n=7-8$ per group).

content were observed when DHPG was administered in the adjacent midbrain reticular formation (Fig. $2 G, H$ ). These findings suggest that acute footshock stress modulates nociceptive signaling by activating $\mathrm{mGlu}_{5}$ and stimulating 2-AG mobilization within the PAG. Consistent with these observations, DHPG increased both the duration $\left(F_{(45,300)}=2.53 ; p=0.003\right)$ and mag-
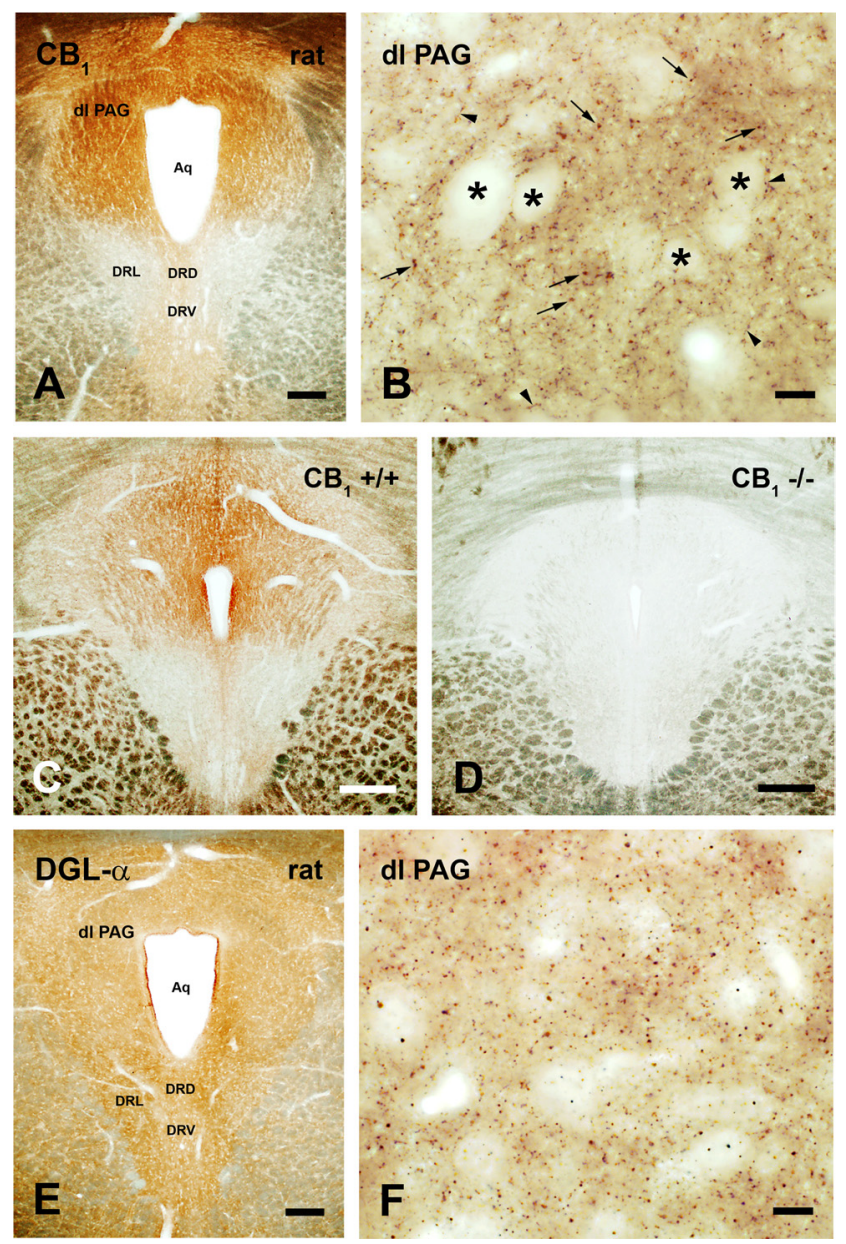

Figure 3. Widespread distribution of $\mathrm{CB}_{1}$ receptors and $\mathrm{DGL}-\alpha$ in the PAG. $A, B$, Light micrographs of $\mathrm{CB}_{1}$ immunostaining in the rat PAG. $A$, The immunoperoxidase reaction revealed strong labeling, especially in the dorsal part of the PAG. Modest immunostaining was observed in the dorsal (DRD) and ventral (DRV) parts of the dorsal raphe nucleus, whereas $\mathrm{C}_{1}$ immunoreactivity was below detection in the lateral part (DRL). $\boldsymbol{B}$, In high-power micrograph, $\mathrm{CB}_{1}$ immunopositive varicosities (small arrows) and thin axonal segments (arrowheads) are visible in the dIPAG. Note basket-like axons showing strong $\mathrm{CB}_{1}$ immunostaining around immunonegative cell bodies (asterisks). $C, D, C B_{1}$ immunolabeling in sections from wild-type and $C_{1}{ }^{-}$ deficient mice. $C$, Immunoperoxidase staining for $\mathrm{CB}_{1}$ receptors in midbrain sections derived from a wild-type $\left(\mathrm{CB}_{1}^{+++}\right)$mouse shows identical $\mathrm{CB}_{1}$ receptor localization pattern to that observed in rats, with highest density of $\mathrm{CB}_{1}$ immunostaining located in the PAG. $D$, Antibody specificity is confirmed by the lack of immunostaining in sections derived from a $C B_{1}$-deficient animal $\left(\mathrm{CB}_{1}^{-1-}\right)$. $\boldsymbol{E}, \boldsymbol{F}$, Light micrographs of DGL- $\alpha$ immunoreactivity in the rat PAG. $\boldsymbol{E}$, High density of DGL- $\alpha$ staining is visible throughout the PAG, including the dIPAG, and the dorsal, ventral, and lateral parts of the dorsal raphe nucleus (DRD, DRV, and DRL, respectively). $F$, At higher magnification, a very dense punctate staining pattern is found in the IIPAG, indicating accumulation of the $D G L-\alpha$ protein within specific subcellular compartments. Abbreviation: $A q$, cerebral aqueduct. Scale bars: $\boldsymbol{A}, \boldsymbol{E} ; \boldsymbol{C}, \boldsymbol{D}, 250 \mu \mathrm{m} ; \boldsymbol{B}, \boldsymbol{F}, 10 \mu \mathrm{m}$.

nitude $\left(F_{(3,20)}=4.59 ; p=0.01\right)$ of stress antinociception and this effect was blocked ( $p=0.005)$ by coinjection of the $\mathrm{CB}_{1}$ antagonist rimonabant [at a dose that did not depress nociceptive responding relative to vehicle $(p=0.609)$ when administered alone] (Fig. 2D). Post hoc analyses revealed that DHPG reliably increased stress antinociception relative to groups receiving vehicle $(p=0.005)$, rimonabant $(p=0.016)$, or rimonabant coadministered with DHPG $(p=0.005)$. Stress antinociception in groups receiving rimonabant alone $(p=0.609)$ or coadministered with DHPG $(p=0.981)$ was similar to that observed in groups receiving vehicle. Thus, DHPG microinjection in the dlPAG triggers 2-AG mobilization to enhance stress antinocicep- 
tion through a mechanism that requires cannabinoid $\mathrm{CB}_{1}$ receptor activation.

\section{Presynaptic $\mathrm{CB}_{1}$ receptors and postsynaptic DGL- $\alpha$ is present in dIPAG}

We next probed the molecular architecture of the sites of action of 2-AG within the PAG. With light microscopy, we observed strong labeling of $\mathrm{CB}_{1}$ in rat PAG, especially in its dorsal aspect (Fig. 3A). At higher magnification, localization of $\mathrm{CB}_{1}$ immunoreactivity to putative varicosities and thin axonal segments was apparent in the dIPAG and other PAG regions (Fig. $3 B)$. Notably, cell bodies in the PAG were immunonegative for $\mathrm{CB}_{1}$, but were surrounded by basket-like axons exhibiting robust $\mathrm{CB}_{1}$ immunoreactivity (Fig. $3 B$ ). A comparable pattern of $\mathrm{CB}_{1}$ immunolabeling was seen in PAG derived from wild-type mice (Fig. 3C), whereas, as expected, $\mathrm{CB}_{1}$ immunoreactivity was absent in the PAG of mutant $\mathrm{CB}_{1}$-deficient mice (Fig. 3D).

We next compared the distribution of $\mathrm{CB}_{1}$ immunoreactivity in the PAG with that of DGL- $\alpha$, the enzyme isoform postulated to control 2-AG formation in the adult CNS. We observed a high density of DGL- $\alpha$ immunoreactivity throughout the PAG, including, but not limited to, the dlPAG (Fig. 3E). Staining for DGL- $\alpha$ was homogeneously distributed in the PAG, but was also present in dorsal, ventral, and lateral parts of the dorsal raphe nucleus

(Fig. 3E). At higher magnification, a punctate staining pattern was observed, which is consistent with accumulation of the enzyme protein within specific subcellular compartments (Fig. $3 F$ ). Based upon these observations, we probed the specific subcellular compartments containing $\mathrm{CB}_{1}$ and DGL- $\alpha$ in the rodent dlPAG. We performed peroxidase immunolabeling followed by highresolution electron microscopy to establish the precise anatomical distribution of these markers in the dlPAG. Our staining demonstrated that $\mathrm{CB}_{1}$ was found presynaptically on axon terminals (Fig. $4 A-D$ ) that were in synaptic connection with dendritic shafts (Fig. 4A), spines (Fig. $4 D$ ), or cell bodies (Fig. 4C). A strikingly high density of $\mathrm{CB}_{1}$ immunoreactivity also occurred on preterminal fibers (Fig. $4 A$ ), as described previously in other midbrain areas (Mátyás et al., 2006). By contrast, DGL- $\alpha$ was situated in a striking postsynaptic position (Fig. $5 A-C$ ), where it was exclusively localized to dendritic shafts (Fig. $5 A, B$ ) and spine heads (Fig. $5 C$ ). Postsynaptic DGL- $\alpha$ and presynaptic $\mathrm{CB}_{1}$ were observed at both excitatory (Figs. $5 A, C, 4 A, D$ ) as well as putative inhibitory (Figs. $5 B, 4 B, C$ ) synaptic specializations of the dlPAG.

\section{DGL- $\alpha$ drives 2-AG accumulation in the PAG and} endocannabinoid-mediated antinociception through activation of the postsynaptic mGlu $_{5}-\mathrm{DGL}-\alpha$ signalosome DGL-mediated hydrolysis of DAG may represent the first committed step in 2-AG biosynthesis (Piomelli, 2003). To probe the molecular mechanisms responsible for 2-AG mobilization in vivo, we examined the impact of pharmacological blockade of
DGL activity on both stress antinociception and 2-AG formation. We microinjected RHC80267 and THL, two structurally distinct compounds that block $2-\mathrm{AG}$ production in vitro by inhibiting the activity of the two known DGL isoforms, DGL- $\alpha$ and DGL- $\beta$ (Bisogno et al., 2003). Injections of either of the two inhibitors into the dlPAG reduced stress-induced antinociception (Fig. 6A, B), whereas off-site injections had no effect $(p=0.26$; Fig. $6 C)$. $\operatorname{RHC} 80267\left(F_{(12,87)}=3.19 ; p=0.001\right)$ and THL $\left(F_{(16,151)}=6.15\right.$; $p<0.0001)$ suppressed stress antinociception in a timedependent manner, and this suppression was maximal immediately following termination of the stressor. The high dose of THL $(10 \mu \mathrm{g})$ suppressed stress antinociception $\left(F_{(3,28)}=4.413 ; p=\right.$ $0.01)$ relative to vehicle $(p=0.004)$ or the lowest dose of THL $(0.1 \mu \mathrm{g} ; p=0.004)$, which failed to alter stress antinocicepion $(p=0.90)$. We also tested the ability of THL, the more potent of the two inhibitors, to block DGL activity in situ. THL microinjections into the dlPAG reduced 2-AG $\left(t_{(15)}=2.12 ; p=0.026\right)$ levels in midbrain punches containing the PAG (Fig. 6E). The injections did not alter anandamide levels $(p=0.657)$ in the same punches (Fig. 6 F). Moreover, 2-AG and anandamide levels in punches obtained from the surrounding midbrain reticular formation were not affected ( $p>0.93$ for each comparison; Fig. $6 \mathrm{G}, \mathrm{H})$. We asked, therefore, whether the ability of $\mathrm{mGlu}_{5}$ activation to potentiate stress antinociception in our studies was dependent upon DGL. The ability of locally administered DHPG ( $p=0.001$ vs vehicle) to potentiate stress-induced antinociception $\left(F_{(30,360)}=5.17 ; p<0.0009\right.$; Fig. $\left.6 D\right)$ was completely 


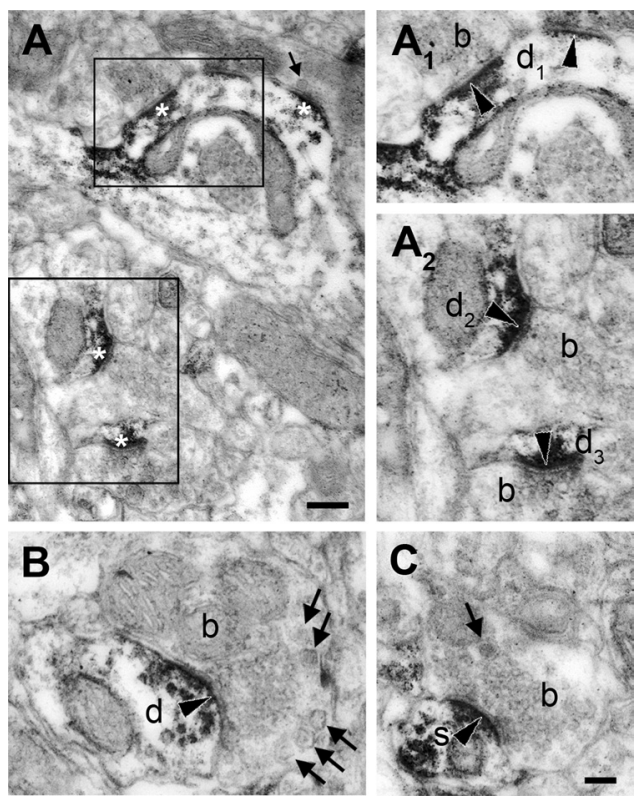

Figure 5. DGL- $\alpha$ is located in dendritic shafts and spine heads situated postsynaptically to axon terminals in the rat dIPAG. $\boldsymbol{A}-\boldsymbol{C}$, High-power electron micrographs of peroxidase-based DGL- $\alpha$ immunostaining demonstrate that DGL $\alpha$, represented by the dense reaction end product (DAB), is located postsynaptically in dendritic shafts $\left(\mathrm{d}_{1-3}\right.$ and $\left.\operatorname{din} A_{1}-B\right)$ and in the heads of dendritic spines (s in $\boldsymbol{C}$ ). The boxed areas in $\boldsymbol{A}$ are enlarged as $\boldsymbol{A}_{1}$ and $\boldsymbol{A}_{2}$. Note that most of the synapses contain DGL- $\alpha$ (indicated by white asterisks in $A$ ). Among the DGL- $\alpha$-negative axon terminals from which the DGL- $\alpha$-containing dendrites receive synapses (labeled with black arrowheads), there are terminals containing round vesicles and others with flat vesicles indicating both excitatory boutons ( $b$ in $A_{2^{\prime}} C$ ) and putative inhibitory axon terminals ( $b$ in $B$ ), respectively. The thick arrows in $\boldsymbol{A}-\boldsymbol{C}$ depict dense core vesicles. Scale bars: $\boldsymbol{A}, 0.2 \mu \mathrm{m}$; $A_{1}-C, 0.1 \mu \mathrm{m}$.

blocked ( $p=0.0009$ vs THL coadministered with DHPG) by a behaviorally inactive dose of THL $(0.1 \mu \mathrm{g})$, microinjected into the dlPAG.

Based upon these observations, we asked whether the $\mathrm{mGlu}_{5}-$ DGL- $\alpha$ signaling complex ("signalosome") is present in dIPAG neurons, where it could control on-demand 2-AG production. To assess colocalization of $\mathrm{mGlu}_{5}$ and DGL- $\alpha$, electron microscopy studies combined immunogold labeling for DGL- $\alpha$ with immunoperoxidase staining for $\mathrm{mGlu}_{5}$. Silver-intensified immunogold particles showed the precise subcellular localization of DGL- $\alpha$ on the cytosolic side of the plasma membrane within dendritic shafts expressing immunoreactivity for $\mathrm{mGlu}_{5}$, which was identified by the diffusible, electron-dense immunoreaction end product diaminobenzidine (Fig. 7A). Moreover, DGL- $\alpha$ and $\mathrm{mGlu}_{5}$ colocalized within the same dendritic spine heads receiving synapses with postsynaptic asymmetrical membrane thickenings (Fig. 7A), indicating the putative excitatory nature of these synapses. The results suggest that DGL- $\alpha$ colocalizes with $\mathrm{mGlu}_{5}$ at postsynaptic sites receiving excitatory synaptic contacts from axon terminals in the dlPAG. However, they do not tell us whether DGL- $\alpha$ is the enzyme that controls stimulationdependent 2-AG formation and endocannabinoid-mediated analgesia in vivo. We, therefore, tested this hypothesis directly by using virally mediated mRNA silencing.

To identify the specific DGL isoform(s) involved in 2-AG formation and stress-induced antinociception, we injected bilaterally into the dlPAG viral vectors directing the expression of shRNAs engineered to silence expression of either DGL- $\alpha$ or DGL- $\beta$ (Jung et al., 2007). Separate groups of rats received identical bilateral injections of either the DGL- $\alpha$ silencing virus
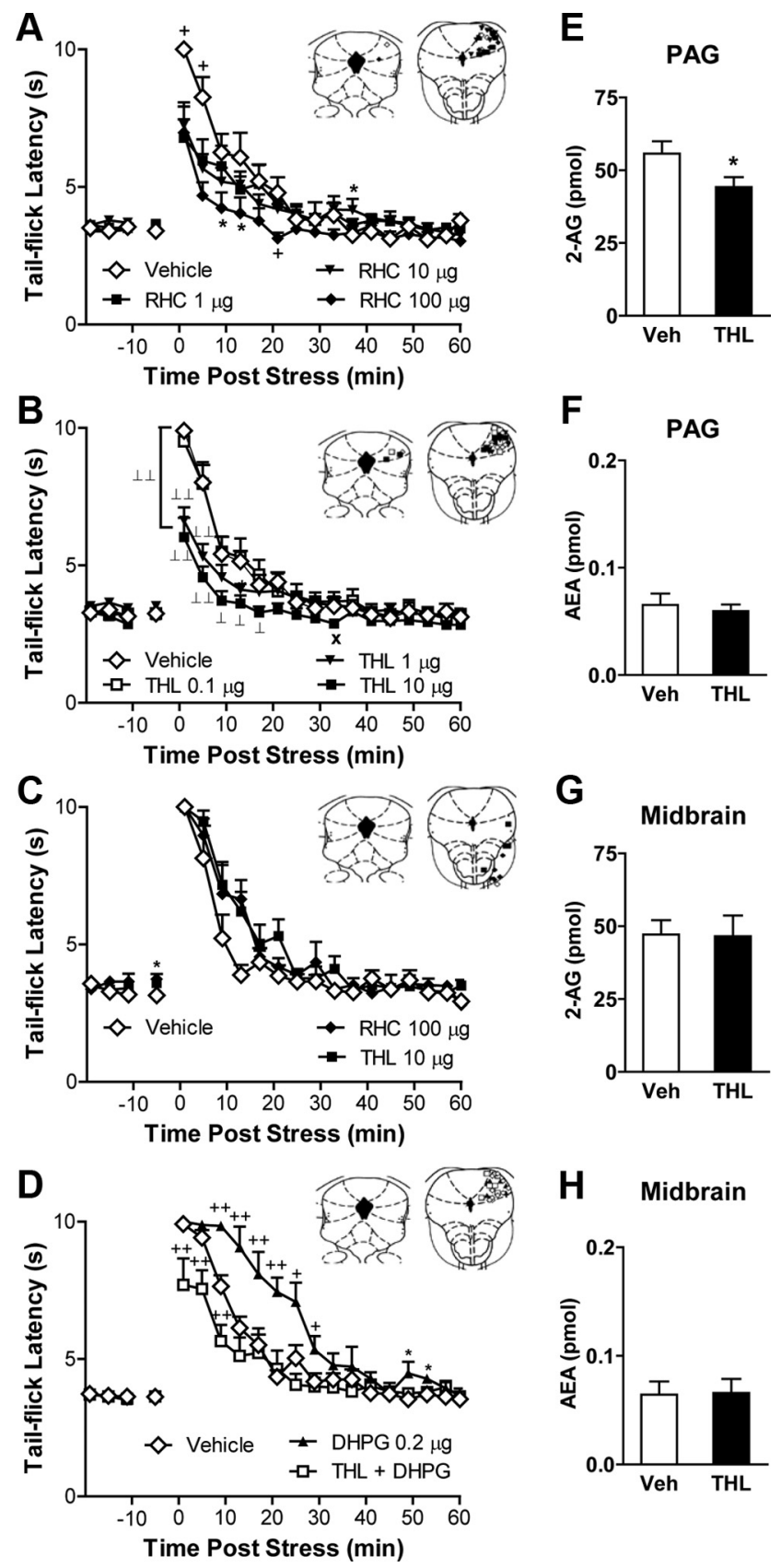

H Midbrain

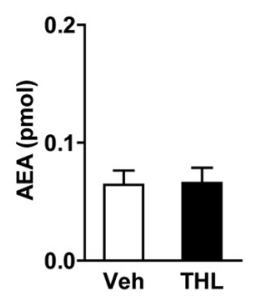

Figure 6. Inhibition of DGL activity in the dIPAG suppresses both endocannabinoidmediated stress antinociception and 2-AG accumulation. $A, B$, Intra-dIPAG microinjection of RHC80267 ( $p=0.001$, ANOVA; RHC, 1, 10, or $100 \mu \mathrm{g}$ ) (A) or tetrahydrolipstatin ( $p<$ 0.0001 , ANOVA; THL, 1 or $10 \mu \mathrm{g}$ ) (B) produced time-dependent suppressions of stress antinociception. THL $(10 \mu \mathrm{g})$ suppressed stress antinociception relative to vehicle $(p<$ $0.01)$ or a behaviorally inactive dose of THL $(0.1 \mu \mathrm{g} ; p<0.01)$. C, Off-site RHC $(100 \mu \mathrm{g})$ or THL $(10 \mu \mathrm{g})$ microinjection failed to alter stress antinociception. D, THL $(0.1 \mu \mathrm{g})$ blocked the DHPG $(0.2 \mu \mathrm{g})$-induced potentiation of stress antinociception $(p<0.001$, ANOVA). $\boldsymbol{E}-\boldsymbol{H}$, Intra-dIPAG microinjection of THL $(10 \mu \mathrm{g})$ decreased 2-AG $(p<0.05$, one-tailed $t$ test; $n=8-9$ per group) (E) but not anandamide $(\boldsymbol{F})$ accumulation in the PAG without altering 2-AG $(\boldsymbol{G})$ or anandamide $(\boldsymbol{H})$ accumulation in the midbrain reticular formation. Data are expressed as mean \pm SEM. Insets, Microinjection sites for groups receiving $1 \mu \mathrm{g}(\boldsymbol{\square}), 10 \mu \mathrm{g}(\boldsymbol{\nabla}), 100 \mu \mathrm{g}(\diamond)$ of RHC80267, $0.1 \mu \mathrm{g}(\square), 1 \mu \mathrm{g}(\boldsymbol{\nabla}), 10 \mu \mathrm{g}$ $(\square)$ of THL, THL plus DHPG $(\square), 0.2 \mu \mathrm{g}$ of DHPG $(\mathbf{\Delta})$ and vehicle $(\diamond)$ in the dIPAG $(\boldsymbol{A}, \boldsymbol{B}$, D) or off-site $(\boldsymbol{C}) .{ }^{*} p<0.05$ versus control; ${ }^{+} p<0.05$ versus all conditions; ${ }^{\times} p<0.05$ versus low dose; ${ }^{\perp \perp} p<0.01,{ }^{\perp} p<0.05$ versus control and low dose (ANOVA, Fisher's PLSD test; $n=6-11$ per group). 
(DGL- $\alpha \mathrm{i})$, the DGL- $\beta$ silencing virus (DGL- $\beta \mathrm{i}$ ), or the LacZ control virus (LacZi) in the dlPAG. Punches containing either the entire PAG (Fig. 8A,B) or offsite control tissue (i.e., midbrain reticular formation) were obtained from animals killed 2 weeks following viral infection, when effects of RNA silencing on behavior were maximal. Silencing the expression of either DGL- $\alpha$ or DGL- $\beta$ in the dlPAG was accompanied by a reduction in DGL activity $\left(F_{(3,24)}=4.58 ; p=0.011\right)$ in midbrain punches containing the entire PAG (Fig. 8C, left), but not in punches prepared from the adjacent midbrain reticular formation ( $p=0.66$; Fig. $8 C$, right). DGL- $\alpha$ i lowered DGL activity relative to LacZi $(p=0.014)$ or off-target injections of DGL- $\alpha \mathrm{i}(p=0.021)$. DGL- $\beta$ i also reduced $\left(t_{(12)}=2.49 ; p=0.029\right)$ DGL activity relative to LacZi treatment in a manner that was indistinguishable from that of DGL- $\alpha \mathrm{i}(p=0.456)$. Notably, DGL- $\alpha$ silencing in the dIPAG was associated with localized decreases in 2-AG $\left(t_{(14)}=2.41 ; p=0.015\right.$; this test was one-tailed based upon the a priori prediction that DGL- $\alpha$ silencing would reduce $2-A G$ production), but not anandamide $(p=0.394)$, levels (Fig. $8 D$ ) in PAG punches. By contrast, DGL- $\beta$ silencing in the dlPAG failed to alter either 2-AG $(p=0.904)$ or anandamide $(p=0.511)$ levels (Fig. $8 E$ ), despite the fact that DGL- $\alpha$ i and DGL- $\beta$ i produced comparable reductions in DGL activity. No changes in endocannabinoid content were observed off-site of the PAG (i.e., in punches derived from the midbrain reticular formation) following RNA silencing of either DGL- $\alpha$ or DGL- $\beta$ (data not shown). The samples used in these analyses were obtained from animals killed at the peak of stress-induced antinociception, 1 min after footshock, when both 2-AG accumulation and antinociception were maximal (Hohmann et al., 2005; Hohmann and Suplita, 2006). RNA silencing of DGL- $\alpha$ in the dlPAG, which reduced 2-AG accumulation in our studies (Fig. $8 D)$, was also associated with localized decreases $\left(F_{(2,7)}=5.21\right.$; $p=0.041)$ in DGL- $\alpha$, but not DGL- $\beta(p=0.859)$, mRNA (Fig. $8 F$ ), further documenting the specificity of virally mediated RNA silencing in downregulating DGL- $\alpha$ mRNA. Moreover, DGL- $\alpha \mathrm{i}$ suppressed DGL- $\alpha$ mRNA relative to LacZi controls $(~ p=0.0269$; this test was one-tailed based upon the a priori prediction that silencing DGL- $\alpha$ transcription would reduce DGL- $\alpha$ mRNA) or off-target injections of DGL- $\alpha \mathrm{i}(p=0.03)$, suggesting that effects of RNA silencing were localized to the PAG. It is likely that our measures underestimate the level of DGL- $\alpha$ silencing induced in dIPAG neurons because microinjections were confined to the dlPAG, whereas lipid and mRNA measurements were made in punches comprising the entire PAG.

To identify a role for DGL- $\alpha$ in behavior, we examined the impact of virally mediated RNA silencing of DGL- $\alpha$ and DGL- $\beta$ in the dIPAG on endocannabinoid-mediated stress antinociception. Separate groups of rats received either identical bilateral injections of viruses engineered to silence either DGL- $\alpha$ (DGL$\alpha \mathrm{i})$ or DGL- $\beta$ (DGL- $\beta \mathrm{i}$ ), the LacZ control virus (LacZi), or no injections (naive rats) (Fig. $8 G-I$ ). Microinjection of the DGL- $\alpha$ silencing virus (DGL- $\alpha \mathrm{i}$ ) into the dlPAG reduced stress-induced antinociception in a time-dependent manner $\left(F_{(20,300)}=2.42\right.$; $p=0.011$ ) (Fig. 8G). This effect was maximal $14 \mathrm{~d}$ after viral infection, when DGL activity, DGL- $\alpha$ mRNA and 2-AG accumu- lation was also selectively reduced in PAG punches (Fig. 8A-F and data not shown). As observed with DGL inhibitors (Fig. $6 A, B)$, the effect of mRNA silencing was greatest immediately following termination of the stressor (Fig. 8G). Moreover, neither virus altered the basal nociceptive threshold (assessed immediately before administration of the stressor) relative to naive groups (Fig. 8G). The DGL- $\alpha$ i virus markedly lowered stress antinociception, producing a $41.6 \%$ decrease in the maximal possible antinociceptive effect (\% MPE) elicited by the stressor at the peak of stress-induced analgesia, which occurred 1 min after termination of footshock (\% MPE, mean \pm SEM: $49.8 \pm 5$ vs $85.3 \pm$ $3.5 \%$ in DGL- $\alpha$ and LacZ groups, respectively; $p<0.0001$, onetailed $t$ test). A statistically robust reduction in stress antinociception was observed relative to naive groups $(p=0.0009)$ or groups receiving bilateral injections of LacZ control virus $(p=$ 0.0009 ) directed at the same dlPAG site when stress antinociception was maximal (Fig. $8 G$ ). Stress antinociception did not differ between LacZi-treated and naive groups $(p=0.515)$ throughout the observation interval. Moreover, DGL- $\alpha$ i selectively suppressed stress antinociception $\left(F_{(2,41)}=5.76 ; p=0.006\right)$. Stress antinociception was lower in groups receiving the DGL- $\alpha$ silencing virus compared with either the DGL- $\beta$ silencing virus ( $p=$ $0.002)$ or the lac $Z$ control virus $(p=0.025)$ (Fig. $8 H)$. By contrast, microinjection of the DGL- $\beta$ silencing virus (DGL- $\beta \mathrm{i}$ ) into the dlPAG did not alter endocannabinoid-mediated analgesia relative to LacZi-treated controls $(p=0.13$; Fig. $8 H$ ). Microinjection of DGL- $\alpha$ i bilaterally into the dlPAG suppressed $\left(F_{(2,20)}=\right.$ $5.15 ; p=0.016)$ stress antinociception relative to either off-target injections of DGL- $\alpha \mathrm{i}(p=0.037)$ or the LacZ control virus $(p=$ 0.009 ; Fig. $8 I)$; this effect was also time dependent $\left(F_{(20,200)}=\right.$ $3.03 ; p=0.002)$. Stress antinociception was similar in groups receiving deliberate off-site bilateral injections of either DGL- $\alpha$ i or LacZi ( $p=0.64$; Fig. $8 I$ ), further documenting the site specificity of virally mediated DGL- $\alpha$ silencing in the PAG. Our results thus provide definitive evidence that DGL- $\alpha$ is the DGL isoform required for both in vivo 2-AG formation and endocannabinoid-mediated stress antinociception. These studies collectively demonstrate that $2-\mathrm{AG}$ is synthesized on demand by activation of an $\mathrm{mGlu}_{5}-\mathrm{DGL}-\alpha$ pathway in the dIPAG to produce 2-AG and endocannabinoid-mediated antinociception in vivo, consistent with a role for 2-AG as a retrograde endocannabinoid messenger. 
A
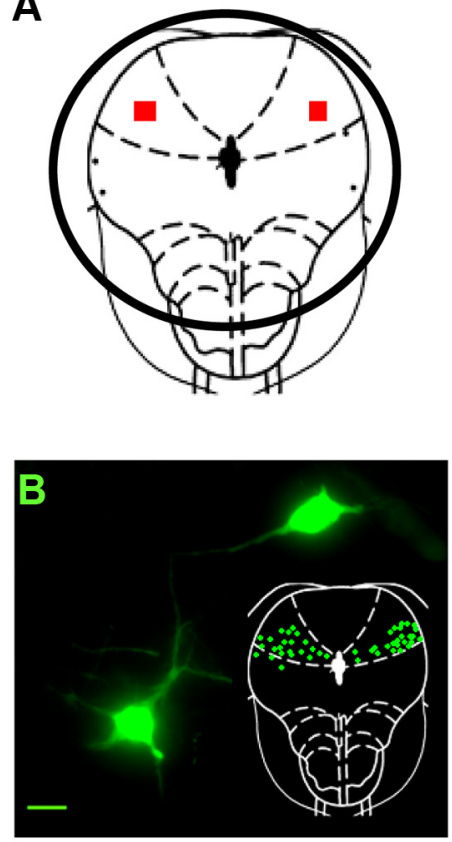

C

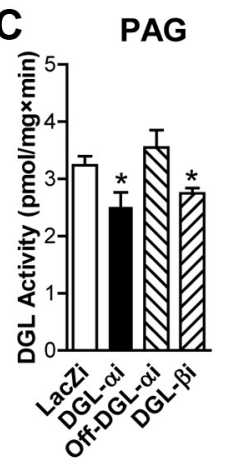

D

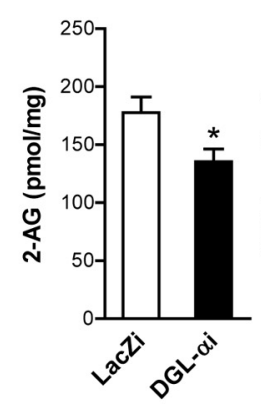

E

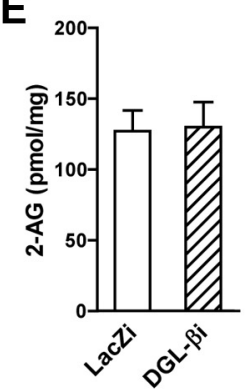

$F$

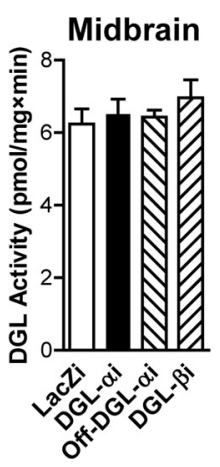

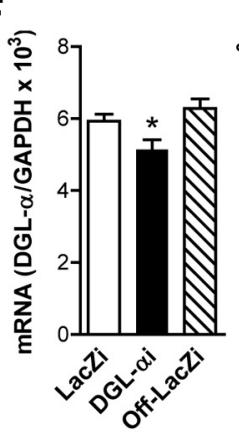

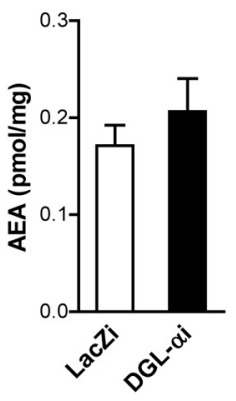

G
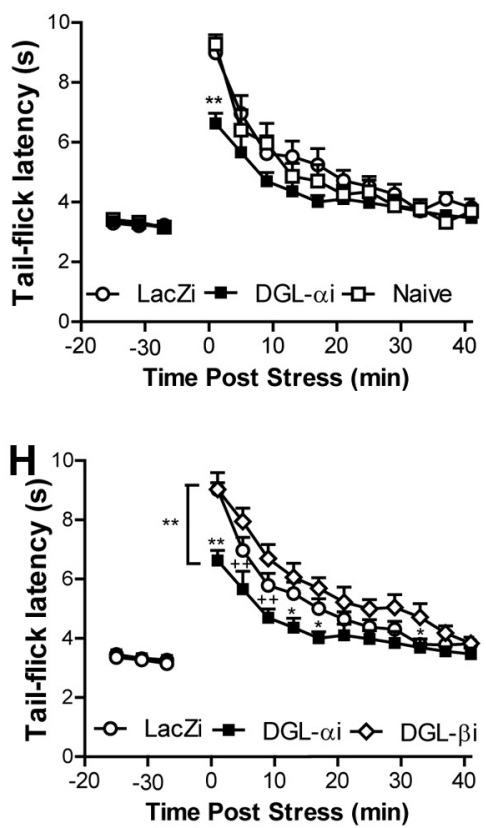

I

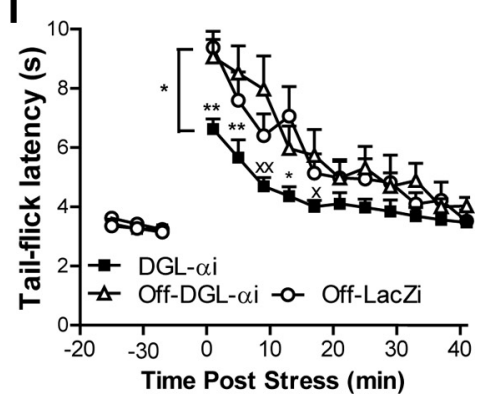

Figure 8. Virally mediated RNA silencing of $D G L-\alpha$, but not $D G L-\beta$, transcription suppresses both endocannabinoid-mediated stress antinociception and 2-AG accumulation in the PAG. $A, B$, Diagram representing the middle of the tissue punch $(A)$, encompassing the level $-6.80 \mathrm{~mm}$ from bregma, which represented the center of the injection sites. $B$, GFP within the expression cassette marks cells in the dIPAG containing DGL- $\alpha$ i shRNA. Inset, Schematic representation of injection sites expressing GFP. C, DGL- $\alpha \mathrm{i}(p=0.01$, Dunnett's test) and DGL- $\beta \mathrm{i}$ ( $p<0.05$, two-tailed $t$ test) shRNAs suppressed ( $p=0.01$, ANOVA) DGL activity in PAG (left panel) but not off-site of PAG in midbrain reticular formation (right panel) ( $n=6-8)$. D, DGL- $\alpha$ i in the dIPAG suppresses 2-AG ( $p<$ 0.05 , one-tailed $t$ test; left panel) but not anandamide (right panel) accumulation in the PAG $(n=8-9)$. E, DGL- $\beta$ i in the dIPAG did not alter either 2-AG (left panel) or anandamide (right panel) levels in the PAG $(n=9) . F$, Intra-PAG DGL- $\alpha$ i suppressed DGL- $\alpha$ mRNA $(p<0.05$, ANOVA; $p<0.05$ for each comparison one-tailed $t$ test; $n=3-4)$ relative to intra-PAG or off-target (left panel) LacZi. DGL- $\alpha$ i shRNA did not alter DGL- $\beta$ mRNA ( $n=3-4$; right panel). $\left(-F\right.$, Data are expressed as mean \pm SEM. ${ }^{*} p<0.05$ versus control conditions (ANOVA and Student's $t$ test). $\mathbf{G}$, Intra-dIPAG DGL- $\alpha$ i shRNA injection suppressed ( $p=0.01$, ANOVA) stress antinociception relative to naive or LacZi-injected controls ( $p<0.05$ for each comparison). $\boldsymbol{H}$, DGL- $\alpha$ i suppressed ( $p<0.01$, ANOVA) stress antinociception relative to DGL- $\beta \mathrm{i}(p<0.01)$ or LacZi $(p<0.05)$ shRNA. I, DGL- $\alpha$ i suppressed ( $p<0.05$, ANOVA) stress antinociception relative to off-target conditions ( $p<0.01$ vs Off-DGL- $\alpha \mathrm{i} ; p<0.05$ vs Off-LacZi). DGL- $\alpha$ i produced time-dependent suppressions $\left(p \leq 0.01\right.$ in G-I, respectively) of stress antinociception; control conditions did not differ $(\mathbf{G}-\mathbf{I})$. ${ }^{* *} p<0.01$, ${ }^{*} p<0.05$ versus all groups; ${ }^{++} p<0.01,{ }^{+} p<0.05$ versus DGL- $\beta \mathrm{i} ;{ }^{\times \times} p<0.01,{ }^{\times} p<0.05$ versus Off-DGL- $\alpha \mathrm{i}$ (ANOVA, Fisher's PLSD test; $n=5-12$ ).

\section{Discussion}

Our results indicate that acute footshock stress suppresses pain sensitivity in vivo by engaging the $\mathrm{mGlu}_{5}-\mathrm{DGL}-\alpha$ signalosome and initiating 2-AG-mediated retrograde signaling in the dlPAG. Several lines of evidence support this conclusion. First, blockade of $\mathrm{mGlu}_{5}$ depressed endocannabinoid-mediated stress-induced antinociception. Second, activation of $\mathrm{mGlu}_{5}$ enhanced stressinduced antinociception while concomitantly stimulating 2-AG production. Third, blockade of DGL activity, established using structurally distinct DGL inhibitors that do not discriminate between the known DGL isoforms, suppressed both stress-induced antinociception and 2-AG formation. Fourth, $\mathrm{mGlu}_{5}$ and the putative 2-AG-synthesizing enzyme DGL- $\alpha$ were colocalized in dendritic spines of the dlPAG, whereas $\mathrm{CB}_{1}$ receptors were confined to axon terminals, consistent with a role for $2-\mathrm{AG}$ as a retrograde signaling messenger. Finally, virally mediated RNA silencing of DGL- $\alpha$, but not DGL- $\beta$, mimicked the effects of pharmacological inhibition of DGL on both stress-induced antinociception and 2-AG accumulation. These studies thus provide direct evidence that 2-AG is synthesized in vivo through activation of the $\mathrm{mGlu}_{5}-\mathrm{DGL}-\alpha$ signalosome and represent, to our knowledge, the first direct demonstration of a functional role for DGL- $\alpha$ in a behavioral paradigm. The implications of this work likely extend beyond endocannabinoid-mediated stress-induced analgesia to include other forms of 2-AG-mediated control of behavior.

Exogenous cannabinoids are known to produce $\mathrm{CB}_{1}$ mediated suppression of both GABAergic and glutamatergic synaptic transmission in the rat PAG in vitro through presynaptic mechanisms, but postsynaptic effects on PAG neurons are strik- 
ingly absent (Vaughan et al., 2000). These electrophysiological findings are consistent with the present results localizing $\mathrm{CB}_{1}$ receptors to both excitatory and inhibitory axon terminals in the PAG, and with the well established primarily presynaptic localization of $\mathrm{CB}_{1}$ throughout the brain (Katona and Freund, 2008). Although a substantial portion of $\mathrm{CB}_{1}$ immunoreactivity is also present on the preterminal segment of the axons, receptors in the axonal plasma membrane do not influence action potential propagation or modulate transmitter release, indicating that the functional location of $\mathrm{CB}_{1}$ receptors was the axon terminal (Mátyás et al., 2006). In PAG slices, neuronal inhibition of glutamate transporters has been shown to enhance $\mathrm{mGlu}_{5}$-mediated control of GABAergic synaptic transmission through a $\mathrm{CB}_{1}$-dependent mechanism (Drew et al., 2008). These in vitro studies suggest that, in the PAG, activation of $\mathrm{mGlu}_{5}$ modulates neuronal excitability by mobilizing an unidentified endocannabinoid mediator. However, a major gap has remained in the present knowledge base to identify this mediator and the biosynthetic pathway responsible for its formation in vivo. Our studies have closed this gap by identifying 2-AG as the endocannabinoid mediator responsible for retrograde signaling in the PAG.

The present work validates a key role for the $\mathrm{mGlu}_{5}-\mathrm{DGL}-\alpha$ pathway in triggering both 2-AG formation and endocannabinoidmediated antinociception. Our studies provide direct evidence implicating a role for on-demand 2-AG formation in behavior. We found that $\mathrm{mGlu}_{5}$ immunoreactivity, localized perisynaptically on dendrites and dendritic spines (Uchigashima et al., 2007), was concentrated in the dorsolateral columns at all levels of the PAG. The dlPAG is implicated in fear-conditioned analgesia (Olango et al., 2012) as well as opioid-independent forms of both stimulation-produced (Walker et al., 1999) and stressinduced (Hohmann et al., 2005) analgesia. Our studies suggest that the role of $\mathrm{mGlu}_{5}$ activation in initiating 2-AG formation may account for the previously unexplained pivotal role of the dlPAG in endocannabinoid-mediated stress-induced analgesia (Hohmann et al., 2005; Hohmann and Suplita, 2006). In the dIPAG, $\mathrm{mGlu}_{5}$ colocalized with the 2-AG synthesizing enzyme DGL- $\alpha$ at postsynaptic sites and stimulation of this pathway triggered both endocannabinoid-mediated antinociception and 2-AG formation. 2-AG was likely to be produced on demand because pharmacological and RNA silencing manipulations did not alter the basal nociceptive threshold in the absence of the stressor. 2-AG, formed via activation of the $\mathrm{mGlu}_{5}-\mathrm{DGL}-\alpha$ signalosome, may thus underlie other nonopioid forms of analgesia (Akil et al., 1976; Lewis et al., 1980; Cannon et al., 1982; Terman et al., 1986) that are mediated specifically by the PAG (Ho et al., 2011; Olango et al., 2012).

An important finding in our studies was that virally mediated RNA silencing of DGL- $\alpha$, but not DGL- $\beta$, suppressed both endocannabinoid-mediated stress antinociception and 2-AG formation. Of note, silencing of DGL- $\alpha$ transcription produced profound deficits in stress antinociception under conditions in which the basal nociceptive threshold was unchanged. These observations further highlight the functional significance of DGL- $\alpha$ in controlling both stimulationcontingent 2-AG production and endocannabinoid-mediated antinociception. These effects were specific for $2-\mathrm{AG}$ because virally mediated RNA silencing of DGL- $\alpha$ in the dIPAG did not alter anandamide levels. By contrast, prior experiments have shown that DGL- $\alpha^{-1-}$ and DGL- $\beta^{-1-}$ mice show marked, parallel reductions in brain 2-AG and arachidonic acid levels, but also substantial decreases in brain anandamide (Gao et al., 2010). In our studies, virally mediated RNA silencing of
DGL- $\alpha$, but not DGL- $\beta$, reduced 2-AG formation and markedly inhibited endocannabinoid-mediated stress antinociception. Sampling methods may have diluted the magnitude of changes in mRNA and/or endocannabinoid content produced by RNA silencing. Nonetheless, it is important to note that both viruses produced comparable reductions in DGL activity in the PAG. It is reasonable to conclude that mobilization of the signaling-competent pool of 2-AG that engages presynaptic $\mathrm{CB}_{1}$ receptors and mediates stress-induced analgesia is under the control of DGL- $\alpha$ rather than DGL- $\beta$. Our studies validate the use of in vivo RNA silencing as a tool for studying DGL- $\alpha$ function that circumvents limitations associated with constitutive, global DGL- $\alpha$ deletion. To our knowledge, the present studies are the first to use and validate in vivo virally mediated RNA silencing with targeted lipidomic analyses.

2-AG and anandamide are mobilized with strikingly dissimilar time courses in dorsal midbrain (Hohmann et al., 2005). This observation suggests that the physiological roles of 2-AG and anandamide in the PAG are not redundant. Because the time course of endocannabinoid-dependent stress antinociception closely correlates with the mobilization of 2-AG, but not anandamide (Hohmann and Suplita, 2006), the present studies focused on uncovering mechanisms responsible for 2-AG formation under physiological conditions. The role of anandamide in the PAG, and the mechanism responsible for its formation in vivo, remain to be elucidated. In the PAG, inhibition of the anandamidehydrolyzing enzyme FAAH (fatty-acid amide hydrolase) produces antinociceptive (de Novellis et al., 2008) and anxiolytic-like (Lisboa et al., 2008) effects and enhances endocannabinoidmediated stress antinociception (Suplita et al., 2005). Inhibitors of endocannabinoid transport also enhance the anxiolytic effects of anandamide (Moreira et al., 2007) and reduce expression of contextual fear conditioning (Resstel et al., 2008) following microinjection into the dlPAG. A role for anandamide in the regulation of anxiety (Moreira et al., 2008) may, therefore, contribute to the distinct time courses of 2-AG and anandamide mobilization in the PAG observed during stressinduced analgesia. Electrical stimulation of the dIPAG also produces both $\mathrm{CB}_{1}$-dependent antinociception and anandamide release in the PAG (Walker et al., 1999). Nonetheless, because 2-AG release was not measured in this latter study (Walker et al., 1999), a role for 2-AG mobilization in contributing to $\mathrm{CB}_{1}$-dependent stimulation-produced analgesia cannot be discounted. More work is necessary to elucidate possible functional interactions between 2-AG and anandamide signaling (Maccarrone et al., 2008) in the PAG. In conclusion, our studies provide the first definitive evidence that activation of the $\mathrm{mGlu}_{5}-\mathrm{DGL}-\alpha$ pathway triggers $2-\mathrm{AG}$ formation in vivo, consistent with a retrograde 2-AG signaling mechanism. A key behavioral consequence of activation of this pathway, antinociception, may be directly attributed to stimulation-contingent formation of 2-AG.

\section{References}

Akil H, Mayer DJ, Liebeskind JC (1976) Antagonism of stimulationproduced analgesia by naloxone, a narcotic antagonist. Science 191:961-962.

Alger BE (2002) Retrograde signaling in the regulation of synaptic transmission: focus on endocannabinoids. Prog Neurobiol 68:247-286.

Alvarez FJ, Villalba RM, Carr PA, Grandes P, Somohano PM (2000) Differential distribution of metabotropic glutamate receptors $1 \mathrm{a}, 1 \mathrm{~b}$, and 5 in the rat spinal cord. J Comp Neurol 422:464-487.

Azkue JJ, Knöpfel T, Kuhn R, Mateos JM, Grandes P (1997) Distribution of the metabotropic glutamate receptor subtype mGluR5 in rat midbrain 
periaqueductal grey and relationship with ascending spinofugal afferents. Neurosci Lett 228:1-4.

Bandler R, Keay KA, Floyd N, Price J (2000) Central circuits mediating patterned autonomic activity during active vs. passive emotional coping. Brain Res Bull 53:95-104.

Bisogno T, Howell F, Williams G, Minassi A, Cascio MG, Ligresti A, Matias I, Schiano-Moriello A, Paul P, Williams EJ, Gangadharan U, Hobbs C, Di Marzo V, Doherty P (2003) Cloning of the first snl-DAG lipases points to the spatial and temporal regulation of endocannabinoid signaling in the brain. J Cell Biol 163:463-468.

Cannon JT, Prieto GJ, Lee A, Liebeskind JC (1982) Evidence for opioid and non-opioid forms of stimulation-produced analgesia in the rat. Brain Res 243:315-321.

Carey MR, Myoga MH, McDaniels KR, Marsicano G, Lutz B, Mackie K, Regehr WG (2011) Presynaptic $\mathrm{CB}_{1}$ receptors regulate synaptic plasticity at cerebellar parallel fiber synapses. J Neurophysiol 105:958-963.

Chevaleyre V, Castillo PE (2003) Heterosynaptic LTD of hippocampal GABAergic synapses: a novel role of endocannabinoids in regulating excitability. Neuron 38:461-472.

de Novellis V, Palazzo E, Rossi F, De Petrocellis L, Petrosino S, Guida F, Luongo L, Migliozzi A, Cristino L, Marabese I, Starowicz K, Di Marzo V, Maione S; Endocannabinoid Research Group (2008) The analgesic effect of $N$-arachidonoyl-serotonin, a FAAH inhibitor and TRPV1 receptor antagonist, associated with changes in rostral ventromedial medulla and locus coeruleus cell activity in rats. Neuropharmacology 55:1105-1113.

Drew GM, Mitchell VA, Vaughan CW (2008) Glutamate spillover modulates GABAergic synaptic transmission in the rat midbrain periaqueductal grey via metabotropic glutamate receptors and endocannabinoid signaling. J Neurosci 28:808-815.

Fukudome Y, Ohno-Shosaku T, Matsui M, Omori Y, Fukaya M, Tsubokawa H, Taketo MM, Watanabe M, Manabe T, Kano M (2004) Two distinct classes of muscarinic action on hippocampal inhibitory synapses: $\mathrm{M}_{2}-$ mediated direct suppression and $\mathrm{M}_{1} / \mathrm{M}_{3}$-mediated indirect suppression through endocannabinoid signalling. Eur J Neurosci 19:2682-2692.

Gao Y, Vasilyev DV, Goncalves MB, Howell FV, Hobbs C, Reisenberg M, Shen R, Zhang MY, Strassle BW, Lu P, Mark L, Piesla MJ, Deng K, Kouranova EV, Ring RH, Whiteside GT, Bates B, Walsh FS, Williams G, Pangalos MN, et al. (2010) Loss of retrograde endocannabinoid signaling and reduced adult neurogenesis in diacylglycerol lipase knock-out mice. J Neurosci 30:2017-2024.

Gerdeman GL, Ronesi J, Lovinger DM (2002) Postsynaptic endocannabinoid release is critical to long-term depression in the striatum. Nat Neurosci 5:446-451.

Giuffrida A, Rodríguez de Fonseca F, Piomelli D (2000) Quantification of bioactive acylethanolamides in rat plasma by electrospray mass spectrometry. Anal Biochem 280:87-93.

Hashimotodani Y, Ohno-Shosaku T, Tsubokawa H, Ogata H, Emoto K, Maejima T, Araishi K, Shin HS, Kano M (2005) Phospholipase Cbeta serves as a coincidence detector through its $\mathrm{Ca}^{2+}$ dependency for triggering retrograde endocannabinoid signal. Neuron 45:257-268.

Hashimotodani Y, Ohno-Shosaku T, Maejima T, Fukami K, Kano M (2008) Pharmacological evidence for the involvement of diacylglycerol lipase in depolarization-induced endocanabinoid release. Neuropharmacology 54:58-67.

Hashimotodani Y, Ohno-Shosaku T, Yamazaki M, Sakimura K, Kano M (2011) Neuronal protease-activated receptor 1 drives synaptic retrograde signaling mediated by the endocannabinoid 2-arachidonoylglycerol. J Neurosci 31:3104-3109.

Ho YC, Lee HJ, Tung LW, Liao YY, Fu SY, Teng SF, Liao HT, Mackie K, Chiou LC (2011) Activation of orexin 1 receptors in the periaqueductal gray of male rats leads to antinociception via retrograde endocannabinoid (2-arachidonoylglycerol)-induced disinhibition. J Neurosci 31:14600-14610.

Hohmann AG, Suplita RL 2nd (2006) Endocannabinoid mechanisms of pain modulation. AAPS J 8:E693-E708.

Hohmann AG, Suplita RL, Bolton NM, Neely MH, Fegley D, Mangieri R, Krey JF, Walker JM, Holmes PV, Crystal JD, Duranti A, Tontini A, Mor M, Tarzia G, Piomelli D (2005) An endocannabinoid mechanism for stress-induced analgesia. Nature 435:1108-1112.

Jung KM, Mangieri R, Stapleton C, Kim J, Fegley D, Wallace M, Mackie K, Piomelli D (2005) Stimulation of endocannabinoid formation in brain slice cultures through activation of group I metabotropic glutamate receptors. Mol Pharmacol 68:1196-1202.

Jung KM, Astarita G, Zhu C, Wallace M, Mackie K, Piomelli D (2007) A key role for diacylglycerol lipase-alpha in metabotropic glutamate receptordependent endocannabinoid mobilization. Mol Pharmacol 72:612-621.

Katona I, Freund TF (2008) Endocannabinoid signaling as a synaptic circuit breaker in neurological disease. Nat Med 14:923-930.

Katona I, Urbán GM, Wallace M, Ledent C, Jung KM, Piomelli D, Mackie K, Freund TF (2006) Molecular composition of the endocannabinoid system at glutamatergic synapses. J Neurosci 26:5628-5637.

Lafourcade M, Elezgarai I, Mato S, Bakiri Y, Grandes P, Manzoni OJ (2007) Molecular components and functions of the endocannabinoid system in mouse prefrontal cortex. PLoS One 2:e709.

Lewis JW, Cannon JT, Liebeskind JC (1980) Opioid and nonopioid mechanisms of stress analgesia. Science 208:623-625.

Lisboa SF, Resstel LB, Aguiar DC, Guimarães FS (2008) Activation of cannabinoid $\mathrm{CB}_{1}$ receptors in the dorsolateral periaqueductal gray induces anxiolytic effects in rats submitted to the Vogel conflict test. Eur J Pharmacol 593:73-78.

Maccarrone M, Rossi S, Bari M, De Chiara V, Fezza F, Musella A, Gasperi V, Prosperetti C, Bernardi G, Finazzi-Agrò A, Cravatt BF, Centonze D (2008) Anandamide inhibits metabolism and physiological actions of 2-arachidonoylglycerol in the striatum. Nat Neurosci 11:152-159.

Maejima T, Hashimoto K, Yoshida T, Aiba A, Kano M (2001) Presynaptic inhibition caused by retrograde signal from metabotropic glutamate to cannabinoid receptors. Neuron 31:463-475.

Mátyás F, Yanovsky Y, Mackie K, Kelsch W, Misgeld U, Freund TF (2006) Subcellular localization of type 1 cannabinoid receptors in the rat basal ganglia. Neuroscience 137:337-361.

Mechoulam R, Ben-Shabat S, Hanus L, Ligumsky M, Kaminski NE, Schatz AR, Gopher A, Almog S, Martin BR, Compton DR (1995) Identification of an endogenous 2-monoglyceride, present in canine gut, that binds to cannabinoid receptors. Biochem Pharmacol 50:83-90.

Moreira FA, Aguiar DC, Guimarães FS (2007) Anxiolytic-like effect of cannabinoids injected into the rat dorsolateral periaqueductal gray. Neuropharmacology 52:958-965.

Moreira FA, Kaiser N, Monory K, Lutz B (2008) Reduced anxiety-like behaviour induced by genetic and pharmacological inhibition of the endocannabinoid-degrading enzyme fatty acid amide hydrolase (FAAH) is mediated by $\mathrm{CB}_{1}$ receptors. Neuropharmacology 54:141-150.

Nyilas R, Gregg LC, Mackie K, Watanabe M, Zimmer A, Hohmann AG, Katona I (2009) Molecular architecture of endocannabinoid signaling at nociceptive synapses mediating analgesia. Eur J Neurosci 29:1964-1978.

Olango WM, Roche M, Ford GK, Harhen B, Finn DP (2012) The endocannabinoid system in the rat dorsolateral periaqueductal grey mediates fearconditioned analgesia and controls fear expression in the presence of nociceptive tone. Br J Pharmacol 165:2549-2560.

Paxinos G, Watson C (1998) The rat brain in stereotaxic coordinates, Ed 4. San Diego: Academic

Piomelli D (2003) The molecular logic of endocannabinoid signalling. Nat Rev Neurosci 4:873-884.

Resstel LB, Lisboa SF, Aguiar DC, Corrêa FM, Guimarães FS (2008) Activation of $\mathrm{CB}_{1}$ cannabinoid receptors in the dorsolateral periaqueductal gray reduces the expression of contextual fear conditioning in rats. Psychopharmacology (Berl) 198:405-411.

Robbe D, Kopf M, Remaury A, Bockaert J, Manzoni OJ (2002) Endogenous cannabinoids mediate long-term synaptic depression in the nucleus accumbens. Proc Natl Acad Sci U S A 99:8384-8388.

Stella N, Schweitzer P, Piomelli D (1997) A second endogenous cannabinoid that modulates long-term potentiation. Nature 388:773-778.

Sugiura T, Kondo S, Sukagawa A, Nakane S, Shinoda A, Itoh K, Yamashita A, Waku K (1995) 2-Arachidonoylglycerol: a possible endogenous cannabinoid receptor ligand in brain. Biochem Biophys Res Commun 215:89-97.

Suplita RL 2nd, Farthing JN, Gutierrez T, Hohmann AG (2005) Inhibition of fatty-acid amide hydrolase enhances cannabinoid stress-induced analgesia: sites of action in the dorsolateral periaqueductal gray and rostral ventromedial medulla. Neuropharmacology 49:1201-1209.

Suplita RL 2nd, Gutierrez T, Fegley D, Piomelli D, Hohmann AG (2006) Endocannabinoids at the spinal level regulate, but do not mediate, nonopioid stress-induced analgesia. Neuropharmacology 50:372-379.

Tanimura A, Yamazaki M, Hashimotodani Y, Uchigashima M, Kawata S, Abe 
M, Kita Y, Hashimoto K, Shimizu T, Watanabe M, Sakimura K, Kano M (2010) The endocannabinoid 2-arachidonoylglycerol produced by diacylglycerol lipase alpha mediates retrograde suppression of synaptic transmission. Neuron 65:320-327.

Terman GW, Morgan MJ, Liebeskind JC (1986) Opioid and non-opioid stress analgesia from cold water swim: importance of stress severity. Brain Res 372:167-171.

Uchigashima M, Narushima M, Fukaya M, Katona I, Kano M, Watanabe M (2007) Subcellular arrangement of molecules for 2-arachidonoylglycerol-mediated retrograde signaling and its physiological contribution to synaptic modulation in the striatum. J Neurosci 27:3663-3676.

Vaughan CW, Connor M, Bagley EE, Christie MJ (2000) Actions of canna- binoids on membrane properties and synaptic transmission in rat periaqueductal gray neurons in vitro. Mol Pharmacol 57:288-295.

Walker JM, Huang SM, Strangman NM, Tsou K, Sañudo-Peña MC (1999) Pain modulation by release of the endogenous cannabinoid anandamide. Proc Natl Acad Sci U S A 96:12198-12203.

Wilson RI, Nicoll RA (2001) Endogenous cannabinoids mediate retrograde signalling at hippocampal synapses. Nature 410:588-592.

Zimmer A, Zimmer AM, Hohmann AG, Herkenham M, Bonner TI (1999) Increased mortality, hypoactivity, and hypoalgesia in cannabinoid $\mathrm{CB}_{1}$ receptor knockout mice. Proc Natl Acad Sci U S A 96:5780-5785.

Zimmermann M (1983) Ethical guidelines for investigations of experimental pain in conscious animals. Pain 16:109-110. 